\title{
2-位官能团化合成 2-取代苯并噻唑的研究进展
}

\author{
戴小强朱亚波汪洲洋翁建全* \\ (浙江工业大学化学工程学院 杭州 310014)
}

\begin{abstract}
摘要 2-取代苯并噻唑类衍生物在化工、医药、农业等领域具有广泛的应用价值. 2-位官能团化是合成 2-取代苯并噻唑 化合物的一种便捷、有效的合成方法. 综述了苯并噻唑 2-位的烷基化、酰基化、芳基化、胺基化以及磷酸化等产物的 合成方法并进行了归类和分析，同时对其发展进行了展望.
\end{abstract}

关键词＼cjkstart苯并噻唑; 2-位官能团化; 烷基化; 酰基化; 芳基化; 胺基化; 磷酸化

\section{Progress in 2-Position Functionalized Synthesis of 2-Substitutedbenzothiazoles}

\author{
Dai, Xiaoqiang Zhu, Yabo Wang, Zhouyang Weng, Jianquan* \\ (College of Chemical Engineering, Zhejiang University of Technology, Hangzhou 310014)
}

\begin{abstract}
Substitutedbenzothiazole derivatives were widely used in chemical, pharmaceutical and agricultural fields. 2-Position functionalized method was a convenient and effective way to synthesize 2-substitutedbenzothiazoles. In this paper, the methods for the synthesis of 2-substitutedbenzothiazoles by the alkylation, acylation, arylation, amination and phosphorylation reactions at the 2-position are reviewed, and their future outlook is also discussed.

Keywords benzothiazole; 2-position functionalization; alkylation; acylation; arylation; amination; phosphorylation
\end{abstract}

苯并噻唑及其衍生物作为一类含氮、硫的稠杂环化 合物, 具有广泛的用途. 由于具有良好的生物活性, 其 作为重要的母体和先导骨架被广泛应用于农药 ${ }^{[1,2]}$ 、医 药 ${ }^{[3 \sim}$ 等药物创制中. 在工业上, 其还可用作橡胶硫化 促进剂 ${ }^{[6]}$ 、塑料染色剂 ${ }^{[7]}$ 等. 鉴于此, 自 1879 年 Hofmann ${ }^{[8]}$ 首次合成了 2-氯与 2-苯基苯并噻唑之后, 对 其的结构修饰和合成便得到了广泛的关注和发展.

苯并噻唑衍生物的结构修饰主要是在苯环上或是 噻唑环 2-位上. 由于 2-位取代基对苯并噻唑衍生物活性 影响较大, 因此其 2-位取代衍生物的合成最受关注 ${ }^{[9]}$. 2取代苯并噻唑的合成主要有两种方法: (1)通过缩合成环 得到 2-位取代的苯并噻唑; (2)采用 2-位官能团化方法在 苯并噻唑的 2-位引入取代基合成 2-取代苯并噻唑. 近年 来 2-取代苯并噻唑的合成方法层出不穷, 关于缩合成环 构建 2-取代苯并噻唑, 王玉炉 ${ }^{[9]}$ 及竺宁 ${ }^{[10]}$ 等已分别按合 成方法和反应底物进行分类对其合成方法进行了详细 总结. 但对于采用 2-位官能团化方法合成 2-取代苯并噻
唑的合成方法，尚无文献对其进行系统总结与讨论. 基 于此, 本文主要根据反应类型的不同, 对近 10 年在金属 催化、非金属催化以及光催化等催化体系下, 采用 2-位 官能团化法合成 2-取代苯并噻唑的研究进行综述和总 结.

\section{2-烷基化苯并噻唑}

苯并噻唑作为一种常见的原料, 其在药物合成、天 然产物以及化工中间体中具有广泛的用途, 因此合成 2烷基化苯并噻唑的方法也得到了广泛的研究. 早在 1994 年, Nishio 课题组 ${ }^{[11]}$ 利用光催化将苯并噻唑-2-硫酮 和烯烃进行 $[2+2]$ 环加成, 再开环制备了 2-取代烷基苯 并噻唑. 这是首次利用光催化方法合成 2-取代苯并噻唑 衍生物.

随后, 2003 年 Kondo 课题组 ${ }^{[2]}$ 报道了一种 $t$-Bu-P4 碱在反应体系中催化芳香烃去质子功能化反应, 实现了

\footnotetext{
* Corresponding author. E-mail: jqweng@zjut.edu.cn

Received March 20, 2017; revised April 9, 2017; published online May 4, 2017.

Project supported by the National Natural Science Foundation of China (No. 30900959) and the Natural Science Foundation of Zhejiang Province (No. LY17C140003).

国家自然科学基金(No. 30900959)和浙江省自然科学基金(No. LY17C140003)资助项目.
} 
苯并噻坐和二苯甲酩的直接偶联反应(Eq. 1). 该反应对 杂环芳烃和甲酮衍生物具有广泛的适用性, 且产率高. 2012 年该课题组 ${ }^{[13]}$ 再次报道了利用胺基取代硅烷和鎓 的氟化物结合实现了脱质子功能烷基化反应. 反应以 P5F 作碱, 胺基取代硅烷 $\left(\mathrm{Me}_{3} \mathrm{SiNR}_{2}\right)$ 作添加剂, 使苯并 噻唑和二苯甲酮直接偶联(Eq. 2). 该体系反应条件温和, 分离产率高, 且对各种芳杂环具有广泛的适用性, 但也 存在反应时间长、碱不易得等缺点.
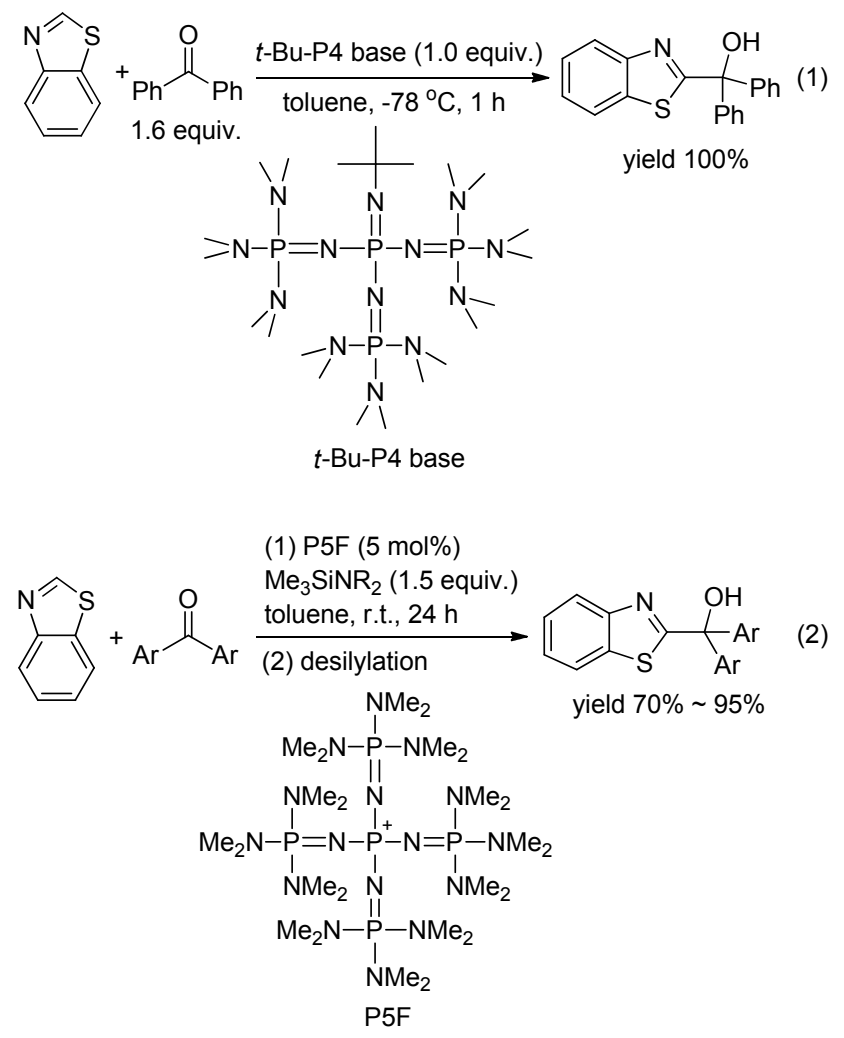

2009 年, Daugulis 等 ${ }^{[14]}$ 在有机碱 $t$-BuOLi 作用下, 促使苯并噻唑和二芳酮发生偶联反应(Eq. 3). 反应体系 简便, 无任何金属催化剂作用, 仅在逐步升温的条件下 就发生酮羰基的还原加成, 并获得 77\%的分离产率. 该 碱廉价易得，反应体系简便.

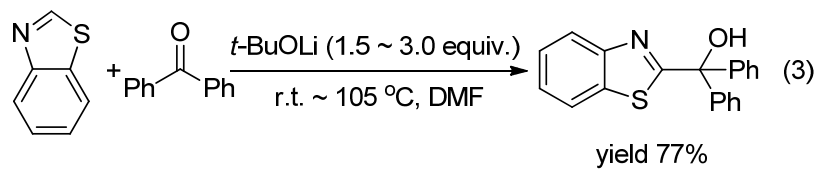

2014 年, Inamoto 等 ${ }^{[15]}$ 以四甲基氟化胺(TMAF)/碱 金属醇盐作活化剂催化了杂芳环去质子功能化反应(Eq. 4). 反应以 TMAF 作氟化物源, $\mathrm{MeOK}$ 作催化剂, $N, N-$ 二 甲基甲酰胺(DMF)作溶剂, 室温下反应 $24 \mathrm{~h}$, 实现了苯 并噻唑和二芳甲酮的烷基化. 该反应具有很高的实用 性, 是一种有效的去质子化方法.

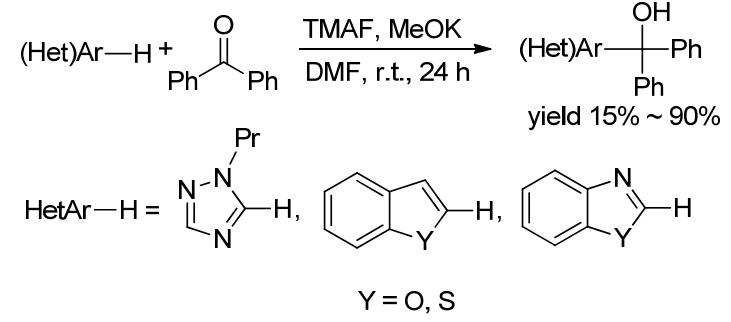

2006 年, Shen 等 ${ }^{[16]}$ 以碱催化了卤代芳杂环 $\alpha$-烷基 化(Scheme 1). 反应以二-(三甲基硅)-氨基钠(NaHMDS) 作碱，甲苯作溶剂，氮气保护下，0 ${ }^{\circ} \mathrm{C}$ 加碱摚拌至室温 反应 $2 \mathrm{~h}$, 再通空气摚拌 $12 \mathrm{~h}$ 得目标产物. 该反应体系 简便、无任何金属催化剂，反应条件温和，且对各种酯、 内酯、酰胺、内酰胺具有广泛的适用性. 但这类反应也 存在操作复杂、不易控制、需氮保等不足.

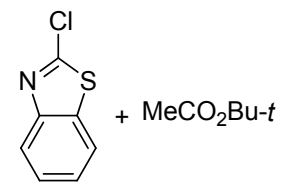

+

图式 1 NaHMDS 催化苯并噻唑 2-位烷基化

Scheme 1 NaHMDS catalyzed 2-position alkylation of benzothiazole

2010 年, Miura 课题组 ${ }^{[17]}$ 报道了钯催化的直接苄基 化反应, 反应以 $2.5 \mathrm{~mol}^{\circ} \mathrm{Pd}_{2}(\mathrm{dba})_{3}$ 作催化剂, $5 \mathrm{~mol} \%$ dppp 作添加剂, 醋酸钠作碱, $120{ }^{\circ} \mathrm{C}$ 反应条件下实现了 目标产物的合成(Eq. 5). 反应得到良好的产率, 且直接 实现了 $\mathrm{C}-\mathrm{H}$ 键的活化.

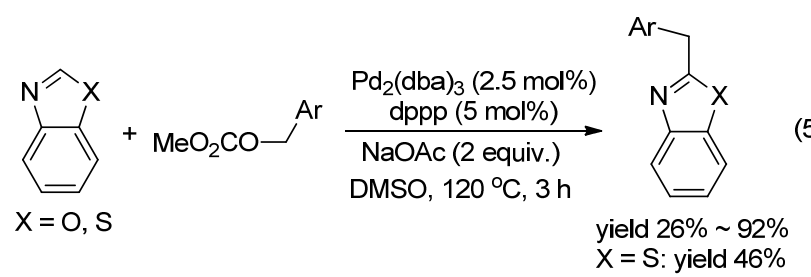

2008 年, Doucet 等 ${ }^{[18]}$ 首次报道了 Pd 催化的芳杂环 和溴代烯烃的烯基化, 反应以 $\mathrm{PdCl}\left(\mathrm{C}_{3} \mathrm{H}_{5}\right)(\mathrm{dppb})$ 作催化 剂, DMF 作溶剂, $\mathrm{Cs}_{2} \mathrm{CO}_{3}$ 作碱, 实现了芳杂环和澳代烷 烯的直接偶联反应(Eq. 6). 该实验证明, 芳杂环功能化 反应具有广泛的适用性，各种卤代烯、卤代芳烃和三氟 甲磺酸类化合物均适用, 且都具有良好的产率. 但反应 体系需高温和氩气保护，反应时间长. 


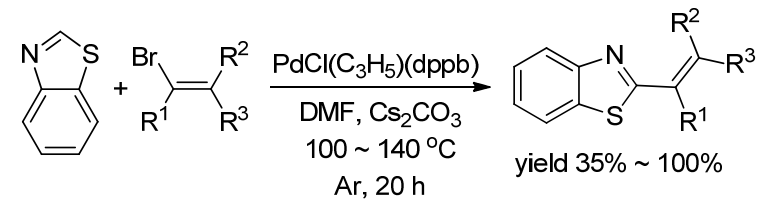

2010 年, Olsson 等 ${ }^{[19]}$ 合成了含苯并噻唑结构的药 物, 在基于功能细胞的测定中被鉴定为钙传感受体 (CaST)的正变构调节剂(PAM). 该反应通过苯并噻唑和 芳香酮的直接偶联得到目标产物(Scheme 2). 反应采用 常规的丁基锂 $/-78{ }^{\circ} \mathrm{C}$ 反应体系, 合成出具有药物活性 的苯并噻唑衍生物, 该类物质的合成进一步说明了苯并 噻唑基团在药物分子创制中的重要作用.
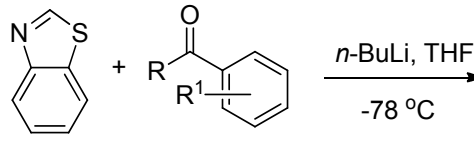
$\mathrm{R}=\mathrm{CH}_{3}$, cyclo- $\mathrm{Pr}$, or $\mathrm{Ph}$
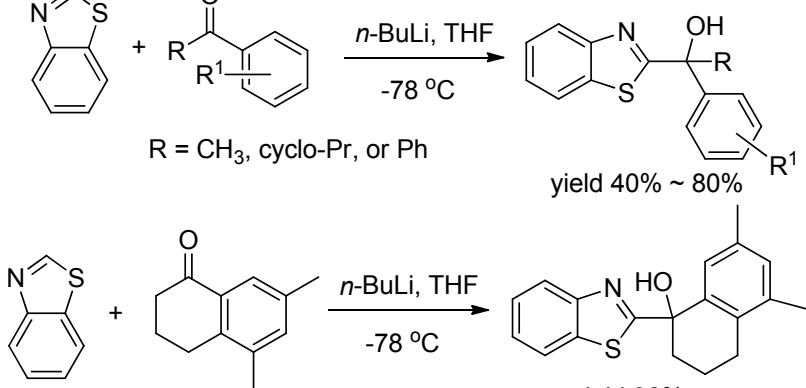<smiles>Cc1cc(C)c2c(c1)C(=O)CCC2</smiles><smiles>Cc1cc(C)c2c(c1)C(O)(c1nc3ccccc3s1)CCC2</smiles>

图式 2 苯并噻唑和芳酮的直接偶联

Scheme 2 Direct coupling of benzothiazole and arone

2011 年，王剑波等 ${ }^{[20]}$ 报道了一种 $\mathrm{Cu}$ 催化的交叉偶 联反应, 在强碱 $t-\mathrm{BuOLi}$ 作用下, 实现了苯并噻(啞)唑的 $\mathrm{C}-\mathrm{H}$ 键活化(Eq. 7). 反应体系先利用 $\mathrm{Cu}$ 催化剂和苯并 噻(啞)唑2-位络合, 再利用 $\mathrm{Cu}$ 的孤对电子和另一底物络 合，再发生迁移，酸化得到目标产物。该反应路径独特、 官能团容忍性好, 且得到良好的分离产率, 对这一类反 应的探究具有重要意义.<smiles>[R][R]1cccc2c1ncn2[Y]</smiles>

随后 2012 年, Prabhu 等 ${ }^{[21]}$ 也采用 Pd 催化的烷基化 反应合成取代烯，反应以 $2.5 \mathrm{~mol} \% \mathrm{Pd}\left(\mathrm{PPh}_{3}\right)_{2} \mathrm{Cl}_{2}$ 作催化 剂, $t$-BuOLi 作碱, $100{ }^{\circ} \mathrm{C}$ 反应条件下实现了 2-卤代苯并 噻唑和腙的烷基化反应(Scheme 3). 相比同类反应，该 体系不需加入其他任何添加剂, 催化剂用量少, 分离产 率高. 同年, Miura 课题组 ${ }^{[22]}$ 也以 $N$-对甲苯磺酰腙为烷 基化试剂, 采用相似的催化条件, 额外加入苯酚作配体, 采用 $\mathrm{Ni} / \mathrm{Co}$-催化实现苯并噁唑(苯并噻唑)的 2-位烷基化 反应(Eq. 8).
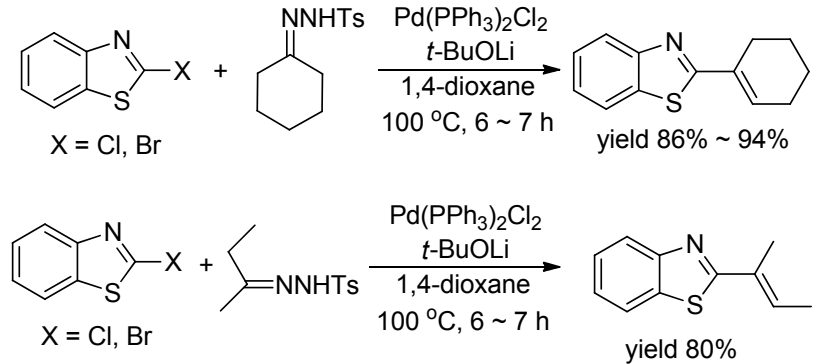

图式 $3 \mathrm{Pd}$ 催化 2-卤代苯并噻唑和腙的烷基化反应

Scheme 3 Palladium catalyzed alkylation reactions of 2-halobenzothiazole with hydrazones

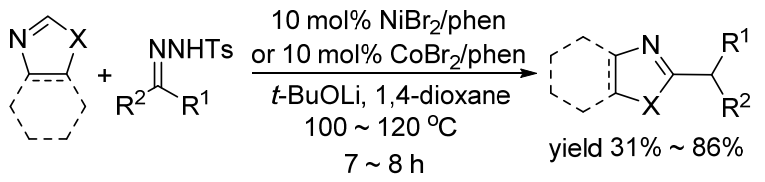

2012 年, 王锐等 ${ }^{[23]}$ 以强碱作金属试剂, 在 $-78{ }^{\circ} \mathrm{C}$ 下首先合成苯并噻唑-锂(钾)试剂，再在添加剂的作用 下，和 $N$-叔丁基亚硫酰基亚胺反应生成 2-位的不对称 选择性偶联产物(Eq. 9). 反应体系中苯并噻唑-锂(钾)试 剂起到非常好的亲核性，反应 $10 \mathrm{~min}$ 得到很好的产率. $\mathrm{R}$ 为取代基是吸电子的芳环能使目标产物的 d.r. $>99$ : 1 , 且给电子芳环有助于提高产率.

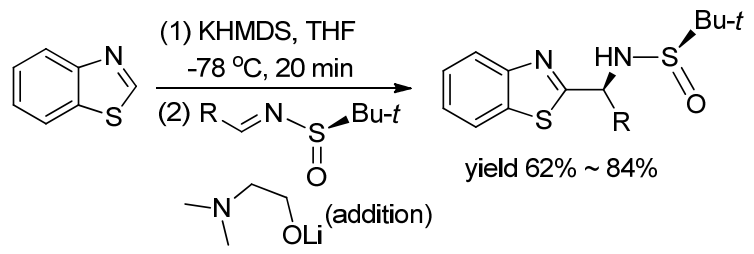

2013 年, Weaver 等 ${ }^{[24]}$ 报道了可见光诱导的 $\mathrm{C}-\mathrm{H}$ 键 功能化偶联反应(Eq. 10). 反应在 $0.75 \mathrm{~mol} \% \operatorname{Ir}(\mathrm{ppy})_{3}$ 作 光催化剂，咪唑作配体，乙腈作溶剂，Blue LED 灯照射 下，实现了 2-氯苯并噻唑和脂肪胺的直接偶联反应. 此 反应体系温和、反应条件简便，且具有很好的区域选择 性.

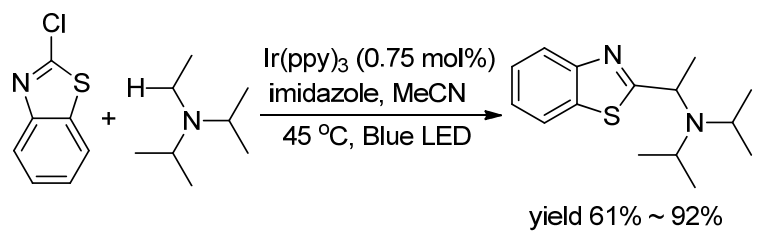

2014 年, O'Shea 等 ${ }^{[25]}$ 以 $\mathrm{Me}_{3} \mathrm{SiO}^{-} / \mathrm{Bu}_{4} \mathrm{~N}^{+}$作活化剂, 在室温条件下促使了三甲基有机硅烷对羰基化合物和 亚胺衍生物的加成反应(Eq. 11). 该反应对各种三甲基 硅烷衍生物具有很广泛的适用性，且反应条件温和、产 率良好。 


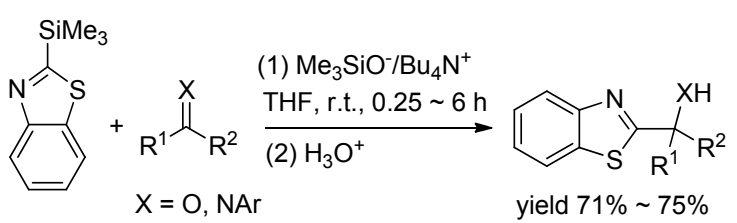

同年，韩建林等 ${ }^{[26]}$ 报道了 Mannich-Type 加成反应 (Eq. 12). 反应通过苯并噻唑和有机碱(丁基锂)反应形成 2-锂化的苯并噻唑, 然后以其作为亲核试剂进攻 $(S)-N$ 叔丁基亚磺酰基-酮亚胺衍生物, 合成了含有两个苯并 噻唑取代基的亚磺酰胺衍生物. 该反应对各种苯并噻唑 衍生物进行了实验，都得到良好的分离产率.

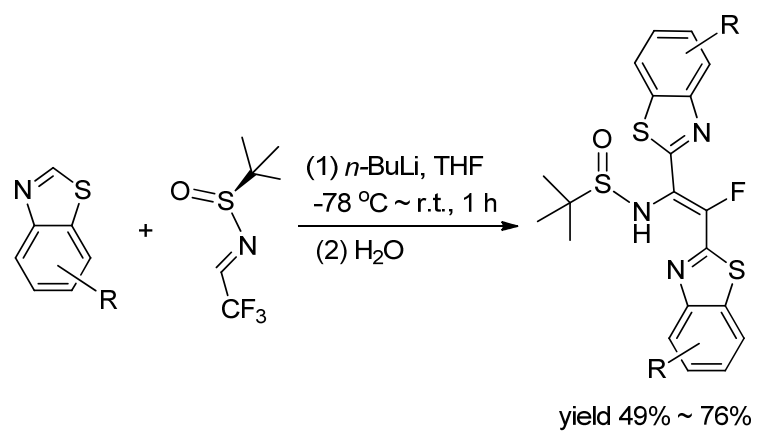

2015 年, 韩建林等 ${ }^{[27]}$ 再次报道了一种相似的不对 称合成氨基-苯并噻唑衍生物的方法，反应体系中以二 异丙基氨基锂(LDA)作碱, 以 2-锂化苯并噻唑作亲核性 试剂去进攻 $(S)-N$-叔丁基亚磺酰基-酮亚胺衍生物合成 目标产物(Eq. 13). 该反应体系拓展了含亚磺酰胺的苯 并噻唑衍生物的合成路径, 这一方法对合成潜在的药物 具有重要的价值, 而且反应具有很好的不对映选择性和 高的分离产率.

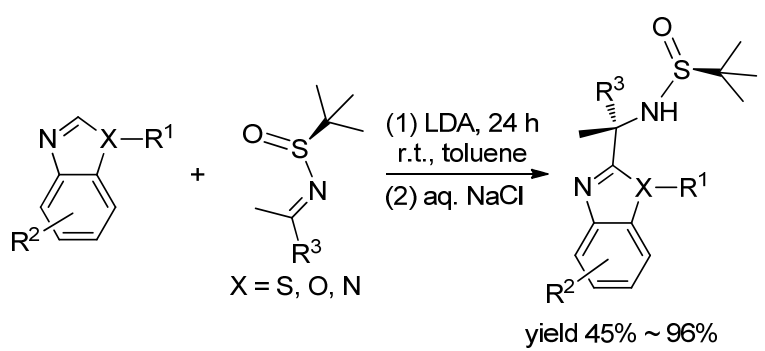

2005 年, Klapars 和 Waldman 等 ${ }^{[28]}$ 以碱催化腈的 $\alpha$ 烷基化反应(Eq. 14). 反应体系以 NaHMDS 或 KHMDS

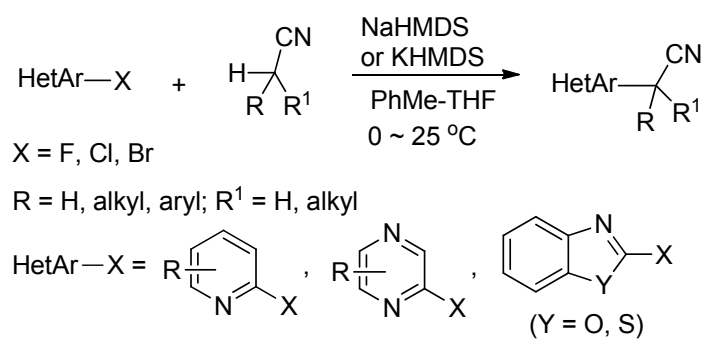

作碱，甲苯或 THF 作溶剂，实现卤代芳杂环和 $\alpha$-烷基腈 的直接偶联. 反应成功的关键在于腈阴离子的形成，促 进了卤代芳杂环的进攻，实现烷基化的偶联，反应对各 种烷基腈、卤代芳杂环具有广泛的适用性，反应简便.

随后，2012 年黄汉民和夏春谷等 ${ }^{[29]}$ 报道了类似于 Miura 课题组的 $\mathrm{Pd}$-催化体系 $\mathrm{Pd}_{2}(\mathrm{dba})_{3} / \mathrm{dppp} / \mathrm{NaOAc}$, 以 $5 \mathrm{~mol} \% \mathrm{Pd}(\mathrm{MeCN})_{2} \mathrm{Cl}_{2}$ 作催化剂, $6 \mathrm{~mol} \% \mathrm{dppp}$ 作配体, 碱的作用下选择性催化杂芳苄基化偶联(Scheme 4). 作 者发现，通过控制使用不同的碱，苯并啞唑和苄氯可以 得到一苄基、二茮基、三苄基偶联产物，苯并噻唑未发 现此现象，仅提供了三苄基偶联产物. 该烷基化体系中, Pd-催化剂在反应中起到至关重要的作用, 碱促进芳杂 环形成 2-位的金属键，也促进了多苄基的形成.

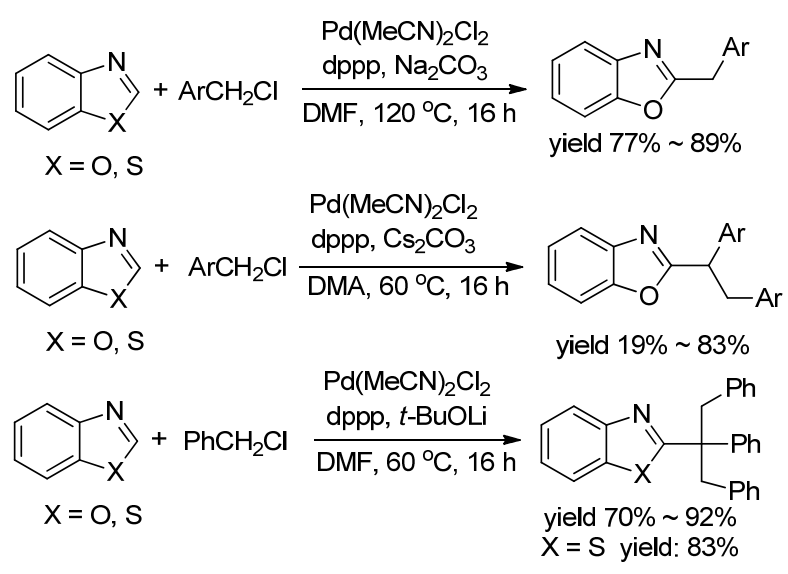

图式 4 Pd 催化芳杂环的亲核加成

Scheme 4 Palladium catalyzed nucleophilic addition of aromatic heterocycles

2013 年, 杨尚东等 ${ }^{[30]}$ 报道了 $\mathrm{Pd}$ 催化的 $\mathrm{C}-\mathrm{H}$ 加成 烷基化反应(Eq. 15). 作者以 $10 \mathrm{~mol} \% \mathrm{Pd}(\mathrm{OAc})_{2}$ 作催化 剂，双齿氮 2,2-二吡啶作配体，二氧六环作溶剂, $100{ }^{\circ} \mathrm{C}$ 条件下实现了 $N$-取代吲哚醌和苯并杂芳的偶联. 该反 应体系无需其他的碱和添加剂，对官能团具有很好的适 应性, 生物测试结果表明该目标产物对肾癌细胞和肝癌 细胞具有很好的抑制作用，对苯并噻唑类化合物应用到 药物合成中具有重要的参考价值.

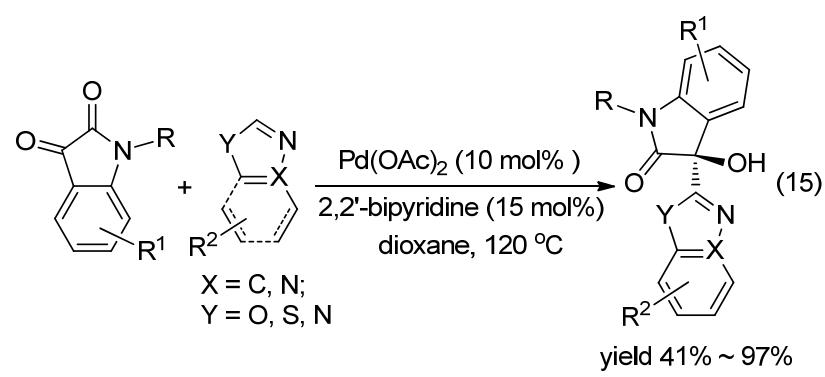

2014 年, 陈晓岗和赵玉芬等 ${ }^{[31]}$ 报道了 $\mathrm{Ag}$ 催化脱羧 促进的苯并噻唑直接烷基化反应(Eq. 16). 反应以 20 
$\mathrm{mol} \% \mathrm{AgNO}_{3}$ 作催化剂, $\mathrm{K}_{2} \mathrm{~S}_{2} \mathrm{O}_{8}$ 作氧化剂, 二氯甲烷/水 作溶剂, 室温下反应 $8 \mathrm{~h}$ 合成了 30 个目标产物。该反应 直接采用烷基羧酸作为烷基化试剂, 原料廉价易得, 反 应条件温和，反应时间短，但是反应催化剂和氧化剂用 量较大.

$$
\begin{aligned}
& \text { r.t., } 8 \mathrm{~h} \text {, } \\
& \mathrm{X}=\mathrm{O}, \mathrm{S} \text { or without } \\
& \text { benzo-subsitue } \\
& \text { yield } 56 \% \sim 96 \%
\end{aligned}
$$

2015 年, Guin 等 ${ }^{[32]}$ 报道了一种氧气介导的脱羧反 应, 实现了芳杂环和醛的 $\mathrm{C}-\mathrm{C}$ 键偶联(Eq. 17). 该反应 首先在氧气作用下将醛氧化成酸, 再进行脱羧和苯并噻 唑反应合成目标产物. 该方法操作简便、环境友好、产 率良好, 且对各种杂环芳烃的 $\mathrm{C}-\mathrm{H}$ 键活化具有广泛的 适用性.

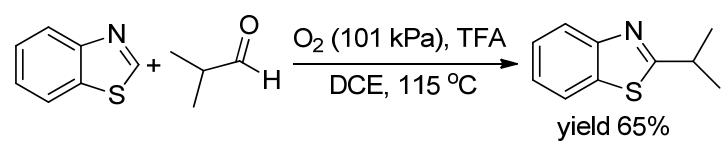

2016 年，黄金波和朱强等 ${ }^{[33]}$ 报道了无过渡金属催 化的酰胺烷基化反应(Eq. 18). 反应以廉价的 $\mathrm{K}_{2} \mathrm{~S}_{2} \mathrm{O}_{8}$ 作 氧化剂, $70{ }^{\circ} \mathrm{C}$ 下反应 $23 \mathrm{~h}$, 促使苯并噻唑和酰胺衍生物 偶联. 该反应是自由基介导的交叉脱氢偶联反应(CDC) 反应，合成路线简便、绿色环保，对替换过渡金属催化 具有重要的参考意义. 但相比同类型反应而言, 反应时 间偏长.
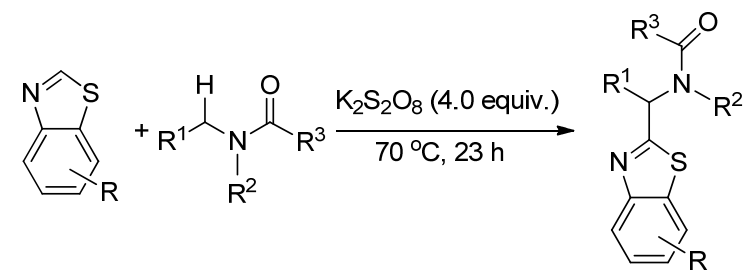

yield $41 \% \sim 80 \%$

同年, Shenvi 等 ${ }^{[34]}$ 报道了一种 $\mathrm{Mn}$ 催化氢电子转移 (HAT)的自由基芳基化 8-芳基薄荷醇的合成. 该反应采 用两步进行, 首先通过 HAT 芳基磺酰氯和异蒲勒醇磺 酰化，再进行芳基迁移、脱磺酰基合成目标产物(Scheme 5). 由于醇官能团的选择性电离导致直接采用 $\mathrm{H}_{2} \mathrm{SO}_{4} / \mathrm{PhH}$ 介导的 Friedel-Crafts 芳基化产物复杂, 故作 者研究了自由基催化的 HAT 烷基化偶联反应. 该反应 设计巧妙，免了 Friedel-Crafts 芳基化的复杂产物、具有 良好的产率, 自由基氢电子转移机理对后续的研究具有
十分重要的参考意义.

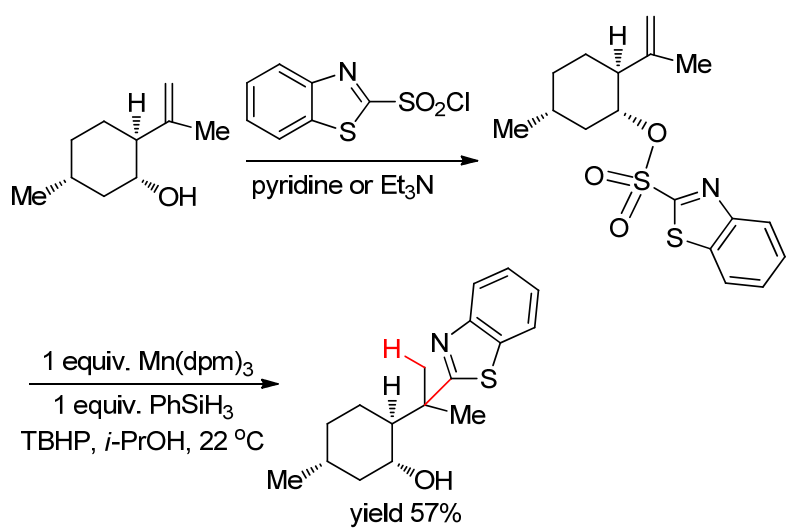

图式 $5 \mathrm{Mn}$ 催化 8-芳基薄荷醇的合成

Scheme 5 Mn-catalyzed synthesis of 8-arylmenthol

2013 年，强琚莉和陈兆旭等 ${ }^{[35]}$ 报道了 $\mathrm{Cu}$ 催化交叉 脱氢偶联反应(Eq. 23). 该反应以 $\mathrm{Cu}(\mathrm{OTf})_{2}$ 作催化剂, $\mathrm{K}_{2} \mathrm{~S}_{2} \mathrm{O}_{8}$ 作氧化剂, $60{ }^{\circ} \mathrm{C}$ 条件下反应 $14 \mathrm{~h}$ 实现了苯并噻 唑和醚的直接偶联. 该反应具有广泛的适用性, 对各种 噻唑衍生物、苯并塞唑衍生物和四氢呋喃、1,4-二氧六 烷均能进行偶联, 且反应条件温和、分离产率良好.

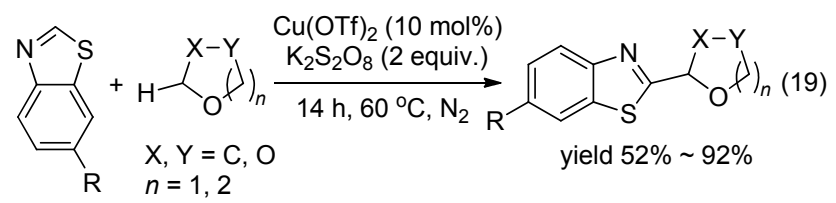

2015 年, Shah 等 ${ }^{[36]}$ 报道了可见光催化的 $\mathrm{C}-\mathrm{H}$ 键功 能化反应(Scheme 6). 该反应在 $\mathrm{K}_{2} \mathrm{~S}_{2} \mathrm{O}_{8}$ 作催化剂, 水作 溶剂, $27 \mathrm{~W}$ CFL 灯照射下实现了醚和缺电子芳烃的直 接偶联. 反应通过光引发使 $\mathrm{K}_{2} \mathrm{~S}_{2} \mathrm{O}_{8}$ 和缺电子芳烃形成 复合物，激发醚自由基的形成，再和缺电子芳烃发生偶 联. 该反应对各种醚具有广泛的适用性，反应条件温和， 溶剂绿色环保等优点.

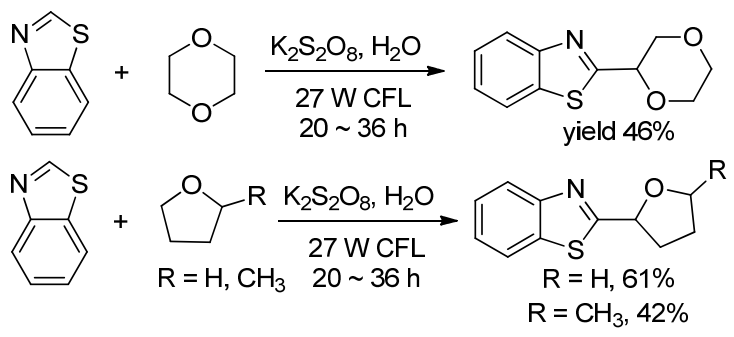

图式 6 可见光诱导的苯并噻唑和醚的反应 Scheme 6 Visible light-induced reactions of benzothiazole with ethers

\section{2-酰基化苯并噻唑}

1971 年, Thames 等 ${ }^{[37]}$ 对 Beel 课题组的方法进行改 
进, 将低温反应体系逐渐升温至室温, 使产率达到 $75 \% \sim 80 \%$. 作者发现该 C-Si 断裂能和氯甲酸乙酯、

醛、邻苯二甲酸酐进行偶联, 形成 2-位的羰基类取代产 物, 且都得到很好的产率(Scheme 7). 该反应体系也存 在着反应敏感、反应温度高等缺点. 2007 年 Koskinen 等 ${ }^{[38]}$ 报道了一种 $\mathrm{CuI} / \mathrm{ZnCl}_{2}$ 催化合成二芳酮的方法(Eq. 20). 此路线是采用很常见的合成方法, $n$ - BuLi 作碱夺取 苯并噻唑 2-位的氢, 再和苯甲酰氯偶联. 反应中二芳酮 主要是以中间体的形式存在, 该杂二芳酮最终是被合成 新型的脂肪酸酰胺水解酶抑制剂, 从而说明苯并噻唑在 新药物合成中具有重要的价值.
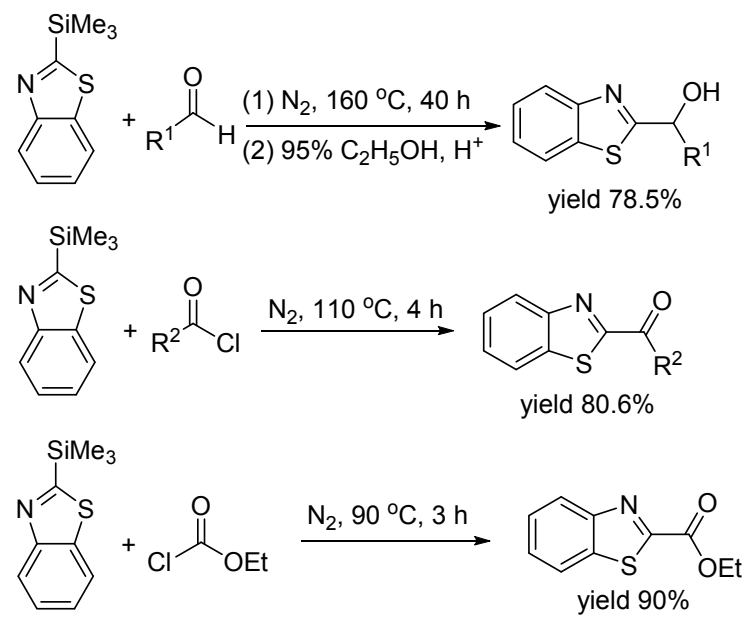<smiles>CSc1nc2ccccc2s1</smiles>
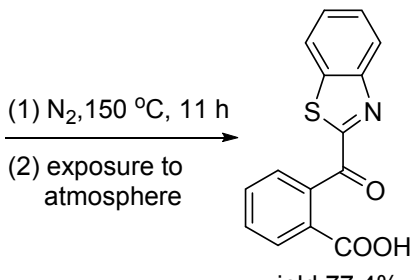

图式 7 2-酰基化苯并噻唑的合成

Scheme 7 Synthesis of 2-acylated benzothiazole<smiles>[X]c1cccc2[nH]c[Y](=O)c12</smiles>

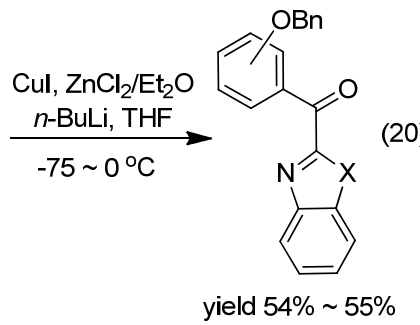

2011 年, 王䂞等 ${ }^{[39}$ 报道了一种新型、简洁、有效的 酰基化反应, 仅以过氧化苯甲酸叔丁酯(TBPB)作氧化 剂, 甲苯作溶剂, 在 $100{ }^{\circ} \mathrm{C}$ 下反应 $12 \mathrm{~h}$ 就实现了苯并噻 唑和甲酰胺的直接脱氢偶联反应(Eq. 21). 该方法的优 点在于不使用金属催化剂、无碱、环境友好、底物适用 性好, 但相比同类反应而言, 所用溶剂污染大, 反应温 度高.

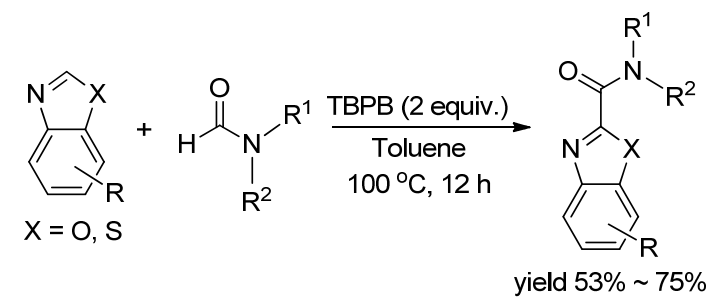

2004 年, 王涛等 ${ }^{[40]}$ 报道了一种以乙腈衍生物作羰 基合成子, 采用一锅法实现了卤代芳烃(杂芳烃)和乙腈 衍生物发生 $\mathrm{S}_{\mathrm{N}} \mathrm{Ar}$ 取代和氧化合成二芳酮(Eq. 22). 反应 体系中采取分步投料方式, NaHMDS 促使 $\mathrm{S}_{\mathrm{N}} \mathrm{Ar}$ 取代反 应的进行, $\mathrm{Na}_{2} \mathrm{O}_{2}$ 起氧化作用. 该反应具有很广泛的适 用性，对卤代芳烃、杂环芳烃、稠杂环芳烃和各种乙腈 衍生物具有很好的反应效果.

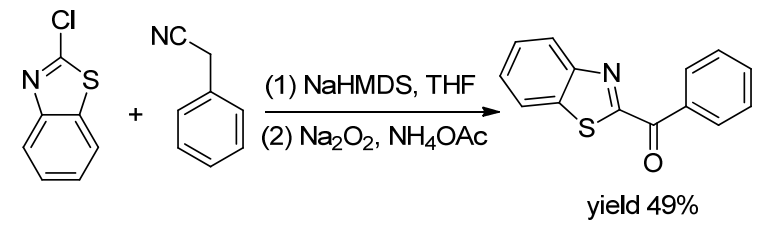

2011 年, 王志刚等 ${ }^{[41]}$ 以最简单的氧化剂 $(\mathrm{NaH} /$ air)来 氧化各种醇成酮(Eq. 23). 该方法对各种杂芳烯丙基醇、 环丙基醇的氧化具有很好的适用性. 反应中对杂芳烯丙 基醇的氧化仅通过 $\mathrm{NaH} / \mathrm{N}_{2}$ 就实现了该反应，但产率不 高, 氢化钠使用及处理也需比较谨慎.

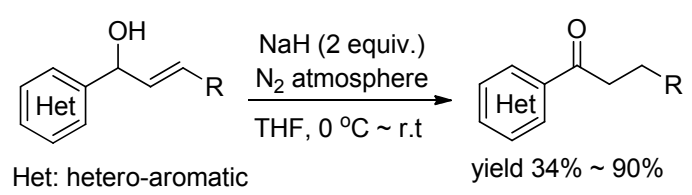

2015 年，雷爱文等 ${ }^{[42]}$ 报道了一种铜催化的选择性 氧化杂芳亚甲基成酮(Eq. 24). 通过控制实验发现，反应 中氯乙酸乙酯充当启动子, 自由基参与整个反应过程, 实现了这一有效的 $\mathrm{C}-\mathrm{H}$ 键氧化和功能化. 该反应对各 种 $N$-杂环化合物具有很好的适用性, 为合成杂环芳酮 提供了新的路径.

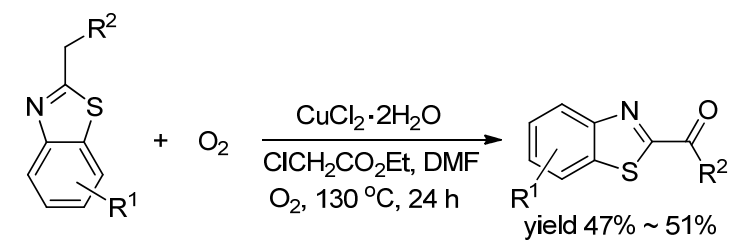

2013 年，吴安心等 ${ }^{[43]}$ 报道了一种 $\mathrm{I}_{2} / \mathrm{KOH}$ 催化的 2烷基酮苯并噻唑的合成方法(Eq. 25). 该反应通过碘氧 化芳酮，苯并噻唑在碱作用下开环，再进行环缩合得到 目标产物. 该反应体系对各种芳酮具有很广泛的适用 
性，且具有很高的分离产率，对合成二芳基酮具有重要 的参考价值. 同年，邓国军等 ${ }^{[44]}$ 报道了 $\mathrm{Fe}$ 催化的 2-芳酮 苯并噻唑的合成, 反应以 $\mathrm{FeCl}_{3} \cdot 6 \mathrm{H}_{2} \mathrm{O}$ 作催化剂, $\mathrm{P}(\mathrm{Cy})_{3} \mathrm{HBF}_{4}$ 作配体, 实现了苯并噻唑 2-位的羰基化反应 (Eq. 26). 作者对这一机理进行阐述, 为先氧化、再开环、 然后环缩合得目标产物. 反应对各种铁盐进行了探究, 均具有不错的催化效果, 通过控制反应条件, 使得 2-芳 基酮为主产物. 但该反应时间长、温度高.
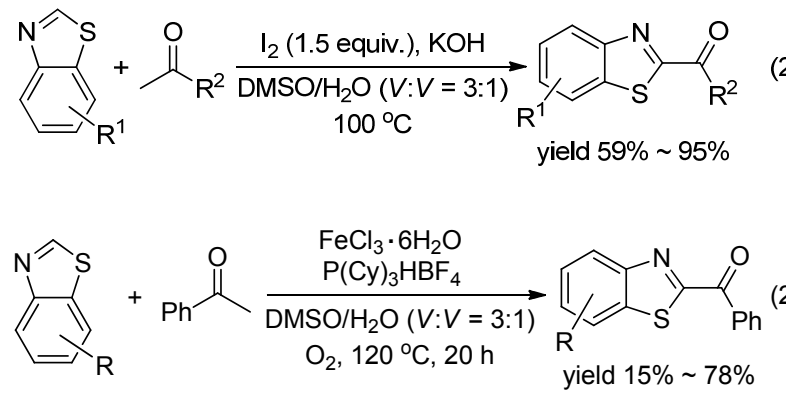

2014 年，宋秋玲等 ${ }^{[45]}$ 以 $\mathrm{CuI}(0.005 \sim 2 \mathrm{~mol} \%$ )作催 化剂, $\mathrm{HBF}_{4}$ 作酸, 经过苯并噻唑的开环和再缩合环化, 实现了苯并噻唑和苯乙酮的偶联(Eq. 27). 该反应具有 催化剂用量少、产率高、对官能团具有很好的容忍性.

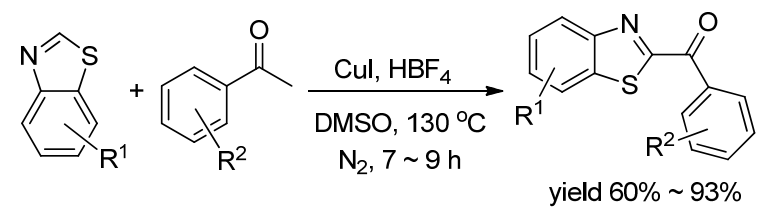

2013 年, 张艳和葛海波等 ${ }^{[46]}$ 报道了 $\mathrm{Ni}$ 催化的脱羧 酰基化, 反应以 $\mathrm{Ni}\left(\mathrm{ClO}_{4}\right)_{2} \cdot 6 \mathrm{H}_{2} \mathrm{O}$ 作催化剂, $\mathrm{Ag}_{2} \mathrm{CO}_{3}$ 作氧 化剂, 苯作溶剂, 实现了 $\alpha$-羰基羧酸脱羧和芳杂环的酰 基化偶联(Eq. 28). 该反应体系对各种芳杂环和羰基羧 酸衍生物具有很好的适用性. 随后, Saxena 等 ${ }^{[47]}$ 也报道 了一种 $\mathrm{Pd}$ 催化铁络合物作氧化剂催化的芳基酮脱羧偶 联(Eq. 29). 反应以 $\mathrm{Pd}(\mathrm{OAc})_{2}$ 作催化剂, [Fe(III)EDTA$\left.\left(\eta^{2}-\mathrm{O}_{2}\right)\right]^{3-}$ 作氧化剂, 水作溶剂, 室温下实现了芳杂环的
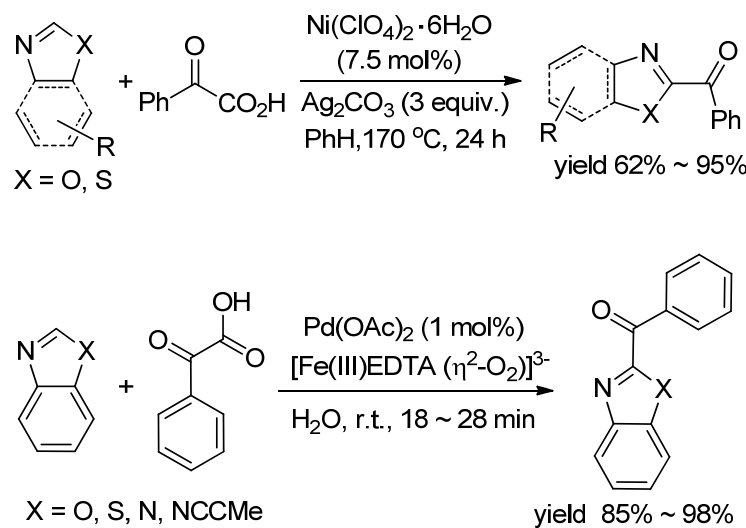

交叉脱羧偶联反应. 相比其他酰基化反应，该催化体系 具有反应条件温和、溶剂绿色环保、分离产率高等优点, 且反应时间短，克服了高温长时间反应的缺点.

2015 年, 陆红健和张艳等 ${ }^{[48]}$ 以 $[\mathrm{Co}] / \mathrm{Ag}_{2} \mathrm{CO}_{3}$ 作共催 化剂, $3-\mathrm{FC}_{6} \mathrm{H}_{4} \mathrm{CF}_{3}$ 作溶剂, 催化 $\alpha$-羰基羧酸脱羧和苯并 噻(噁)唑发生交叉偶联反应(Eq. 30). 该体系中 $\mathrm{Ag}_{2} \mathrm{CO}_{3}$ 促使脱羧反应, [Co]催化剂和芳杂环 2-位络合, 再进行 偶联生成 2-羰基芳杂环衍生物. 该反应得到很好的分离 产率，对芳杂环衍生物具有很好的适用性，该类催化体 系对芳杂环衍生物 2-位 C- $\mathrm{H}$ 键活化的研究具有重要意 义.

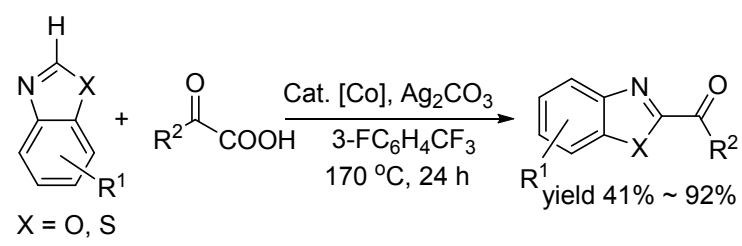

2013 年, $\mathrm{Hu}$ 等 ${ }^{[49]}$ 报道合成了一种含苯并噻唑-2-芳 酮的新药(Eq. 31). 该反应在 LDA, $-70{ }^{\circ} \mathrm{C}$ 低温条件下, 实现了 4-取代苯甲酸甲酯和苯并噻唑的二芳酮合成. 该 产物可作为合成目标药物的中间体，对苯并噻唑衍生物 应用于药物合成中具有重要的借鉴价值.

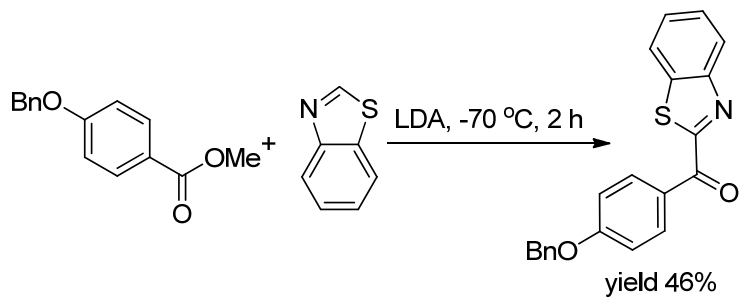

随后, 2014 年，陈晓岗和屈凌波等 ${ }^{[50]}$ 报道了以无金 属催化体系过氧化物催化的苯并噻唑酰基化(Eq. 32). 反应以 TBHP 作氧化剂, 乙腈作溶剂, $80{ }^{\circ} \mathrm{C}$ 反应 $24 \mathrm{~h}$ 就 实现了磷酸酯作为酰基化试剂的偶联. 该反应体系通过 TBHP 氧化磷酸酯中的 $\alpha$-位亚甲基形成自由基，然后进 攻苯并噻唑实现氧化偶联反应. 反应对各种取代基具有 广泛的适用性, 且具有不错的分离产率.

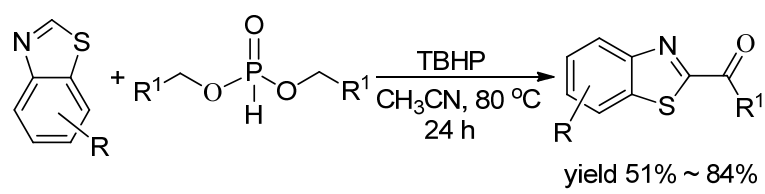

2015 年, Eycken 等 ${ }^{[51]}$ 报道了 $\mathrm{Pd}$-催化的杂芳 $\mathrm{C}\left(\mathrm{sp}^{2}\right)-\mathrm{H}$ 功能化(Eq. 33). 反应以 $\mathrm{Pd}(\mathrm{OAc})_{2}$ 作催化剂, Xantphos 作配体, $\mathrm{Cs}_{2} \mathrm{CO}_{3}$ 作碱, 异腈作插入体, 分两步 实现杂芳的酰基化反应. 该反应体系打破固定的直接氧 
化、脱羧偶联等方法, 采用异腈作插入体先和卤代苯偶 联, 再和杂芳酰化得到目标产物, 合成方法路径新颖, 但反应体系太复杂，后处理困难，反应条件也不温和.

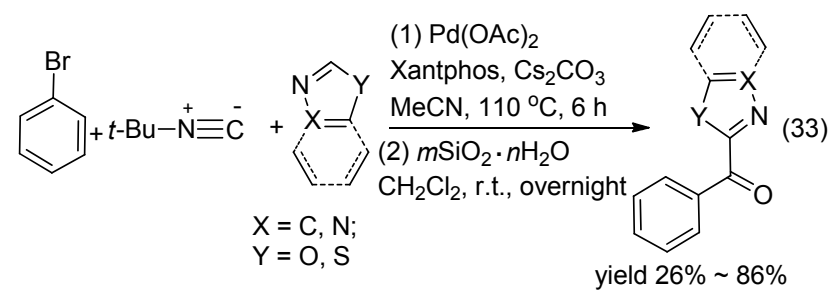

2016 年, Miura 等 ${ }^{[52]}$ 报道了一种无金属的催化体系, 以空气作氧化剂, 在可见光下, 实现了 2-甲基芳杂环的 吸氧催化氧化成醛反应(Eq. 34). 反应中 $\mathrm{I}_{2}$ 先插入, 再发 生 $\mathrm{C}-\mathrm{I}$ 键均裂氧化成目标产物, 该反应避免了过渡 金属催化的不足，反应条件温和、高效. 同年, 季海涛等 ${ }^{[53]}$ 报道了苯甲醛介导的光氧化还原交叉脱氢偶联反应 (CDC) (Eqs. 35，36). 该反应在以苯甲醛作光敏剂, $(\mathrm{NH})_{4} \mathrm{~S}_{2} \mathrm{O}_{8}$ 作催化剂, $\mathrm{CFL}$ 灯的照射下实现了苯并噻唑 和 $N, N$-二取代乙酰胺(或甲酰胺)脱氢偶联反应. 相比于 过渡金属催化的反应，此反应具有条件温和、环境友好、 绿色节能等优点.
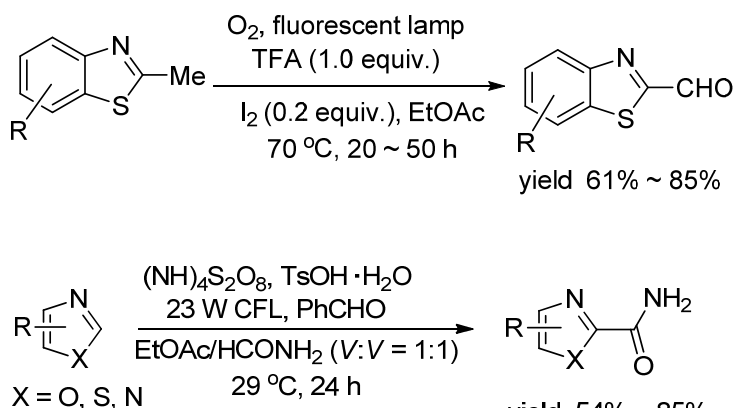

$$
\mathrm{X}=\mathrm{O}, \mathrm{S}, \mathrm{N} \quad 29^{\circ} \mathrm{C}, 24 \mathrm{~h} \quad \text { yield } 54 \% \sim 85 \%
$$

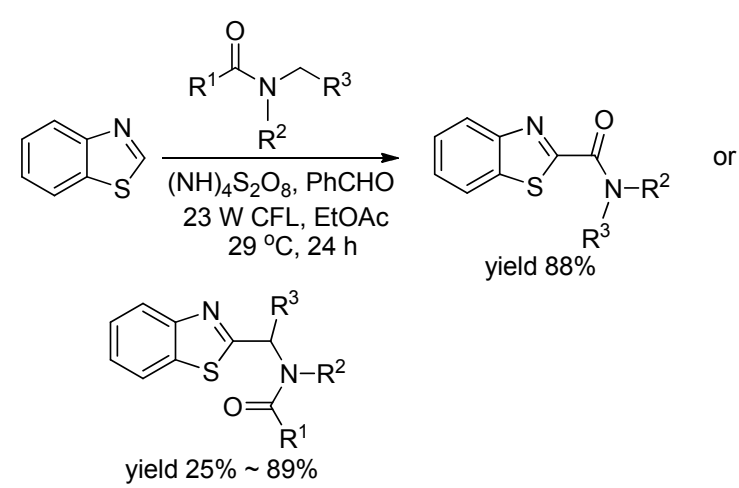

\section{2-芳基化苯并噻唑}

由于杂环-芳环骨架结构在许多天然产物、医药、 功能材料中随处可见，因此在有机合成中芳基化的杂环 化合物的合成方法得到广泛的关注 ${ }^{[54]}$. 过渡金属催化
的交叉偶联是最可靠的方法之一，其中包括了卤代芳烃 的偶联、芳醛作芳基化试剂促进的开环再环合偶联以及 直接催化 $\mathrm{C}-\mathrm{H}$ 键活化的交叉偶联反应.

2009 年, Miura 等 ${ }^{[55]}$ 报道了 $\mathrm{Ni}$ 催化的直接芳基化, 反应以 $\mathrm{NiBr}_{2}$ 作催化剂, 1,10 -邻菲罗啉作配体, $t$-BuOLi 作碱, 二甘醇二甲醚作溶剂, $150{ }^{\circ} \mathrm{C}$ 实现了苯并噻唑(苯 并噁唑)和澳代苯衍生物的直接偶联(Eq. 37). 该体系对 各种溴代芳烃均具有很好的适用性，且具有良好的产 率. 但反应催化体系用量大、反应温度高.

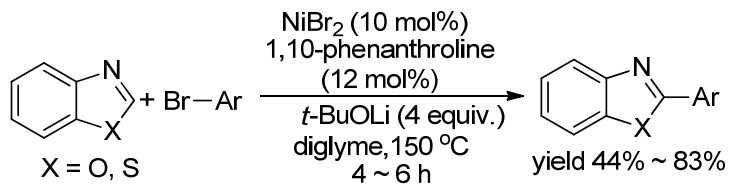

同年, Itami 课题组 ${ }^{[56]}$ 以 $\mathrm{Ni}$ 催化实现了卤代芳烃和 芳杂环化合物的直接偶联(Eq. 38). 反应以 $\mathrm{Ni}(\mathrm{OAc})_{2}$ 作 催化剂, bipy 作配体, $t$-BuOLi 作碱, 实现了目标产物的 合成. 该方法被初步证实了可用于快速合成一种用于痛 风和高尿酸血症的药物非布索坦. 且该催化体系能实现 苯并噻唑和各种卤代芳烃、卤代芳杂环的偶联，具有良 好的催化效果.

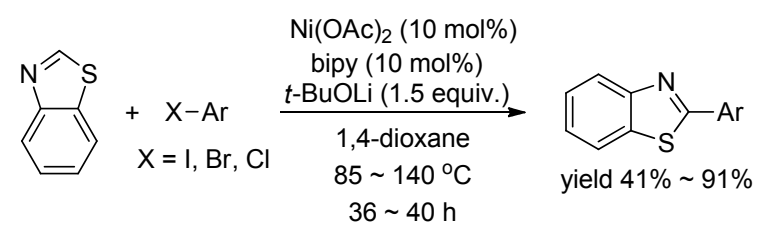

2010 年, Gosmini 等 ${ }^{\left[{ }^{[7]}\right.}$ 报道了钴-催化的 C-SMe 键 活化，实现了杂芳环的交叉偶联反应(Eq. 39). 反应在 $\mathrm{CoBr}_{2} / \mathrm{Zn}$ 的催化下, 先使澳代苯生成格氏试剂, 再断杂 芳硫醚中的 $\mathrm{C}-\mathrm{S}$ 键实现目标产物的偶联. 同年, Ranu 等 ${ }^{[58]}$ 以 $\mathrm{Pd}$ 纳米颗粒催化了芳基化反应，反应以 $\mathrm{Pd}(\mathrm{OAc})_{2} / \mathrm{TBAB}$ 作催化剂, $\mathrm{K}_{2} \mathrm{CO}_{3}$ 作碱, $\mathrm{AgOAc}$ 作添加 剂，分子篎干燥的条件下实现了苯并噻唑和碘代芳烃的 直接偶联(Eq. 40). 反应中通过 Pd 和碘代芳烃偶联成 $\mathrm{ArPdI}$, 再在添加剂的作用下产生 Pd 阳离子亲电子中间 体，碱最后促进偶联的形成. 该反应对各种碘代芳烃衍 生物均适用, 且具有良好的分离产率. 但该反应体系复 杂、不易处理、催化剂添加剂昂贵，且反应温度高、反 应时间长.

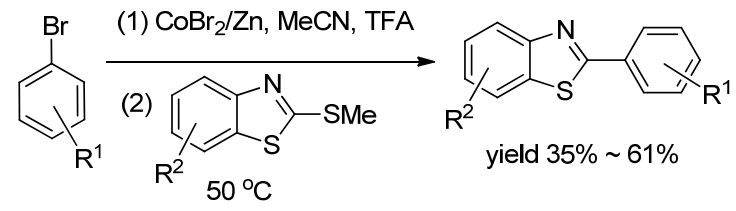




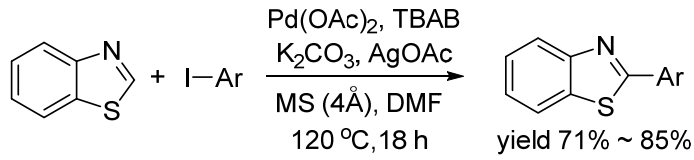

2011 年，黄志真等 ${ }^{[59]}$ 报道了一种实用的 $\mathrm{Pd}-\mathrm{Cu}$ 共催 化体系, 采用廉价的 $\mathrm{PPh}_{3}$ 作配体, 实现了苯并噻唑(苯 并噁唑)和溴代芳烃的直接偶联反应(Eq. 41). 该反应体 系条件温和、操作简便, 且得到很好的产率. 随后, Itami 课题组 ${ }^{[60]}$ 采用 $\mathrm{Ni}$ 催化了芳基化偶联反应(Eq. 42). 反应 在 $\mathrm{Ni}(\mathrm{OAc})_{2} / \mathrm{bipy} / t$-BuOLi 催化体系中进行, $120{ }^{\circ} \mathrm{C}$ 条件 下实现芳基化反应, 相比 $\mathrm{Pd}-\mathrm{Cu}$ 体系, 该体系更廉价环 保. 并且该方法被成功应用于合成黄嘌呤氧化酶抑制剂 (有效治疗痛风和高尿酸血的药物)、氯苯唑酸[有效治疗 TTR-FAP(转甲状腺素蛋白相关性家族性淀粉样多发性 神经病)药物]以及具有抗结核活性的天然产物.
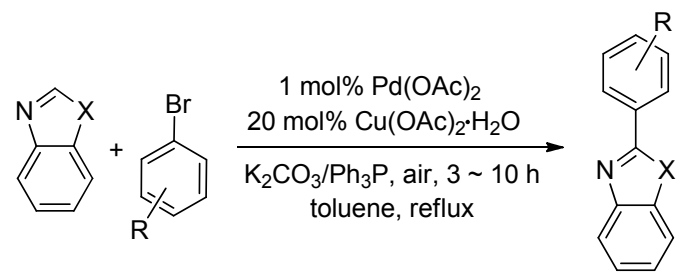

$\mathrm{X}=\mathrm{O}, \mathrm{S}, \mathrm{NMe}$ yield $75 \% \sim 93 \%$

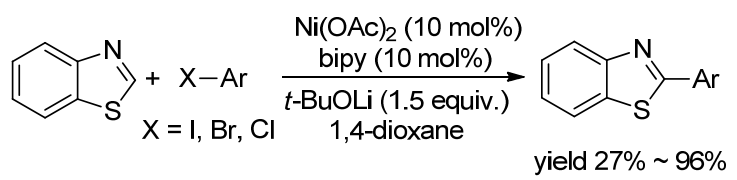

2014 年, Hong 等 ${ }^{[61]}$ 报道了一种 $\mathrm{Cu}$ 介导的 $\mathrm{C}-\mathrm{H}$ 键 功能化反应, 实现苯并噻唑的 2-位官能团化(Eq. 43). 在 反应体系中强碱夺取苯并噻唑 2-位的氢使其和 $\mathrm{Cu}$ 离子 形成 2-位络合，3-碘代喹诺酮再和苯并噻唑铜络合物发 生氧化加成、还原消除得到目标产物. 该反应体系具有 高效、反应方便、适用性广等特点, 但也存在反应条件 不够温和、需高温和氮气保护且反应时间长等缺点.<smiles>[R]c1ccc2c(=O)c(I)cn(Cc3ccccc3)c2c1</smiles><smiles>[R]c1ccc2nc([R])sc2c1</smiles>
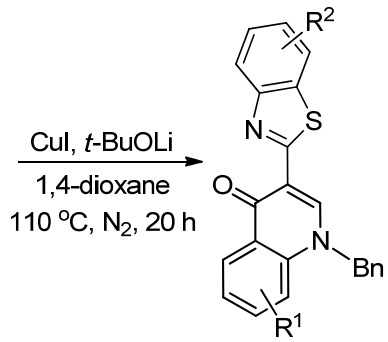

yield $51 \% \sim 91 \%$

Punji 课题组 ${ }^{[62]}$ 合成了单核和双核钯的螯合物，并
将其应用于催化区域选择性 $\mathrm{C}$ - $\mathrm{H}$ 键活化，实现了苯并 噻唑和对甲基碘苯的芳基化反应，得到 $95 \%$ 的分离产率 (Eq. 44). 随后在 2016 年, 该课题组 ${ }^{[63]}$ 再次报道了在一 种 $\mathrm{Pd}$ 的螯合物和 $\mathrm{CuI}$ 共催化的作用下，实现了苯并噻唑 和对甲基碘苯的芳基化(Eq. 45). 作者研究发现，反应路 径是以 $\mathrm{Pd}^{\mathrm{II}}-\mathrm{Pd}^{\mathrm{IV}}-\mathrm{Pd}^{\mathrm{II}}$, 反应先是苯并噻唑和 $\mathrm{CuI}, \mathrm{Pd}$ 螯合 剂进行偶联，对甲基碘苯进行氧化加成，再进行还原消 除得目标产物.
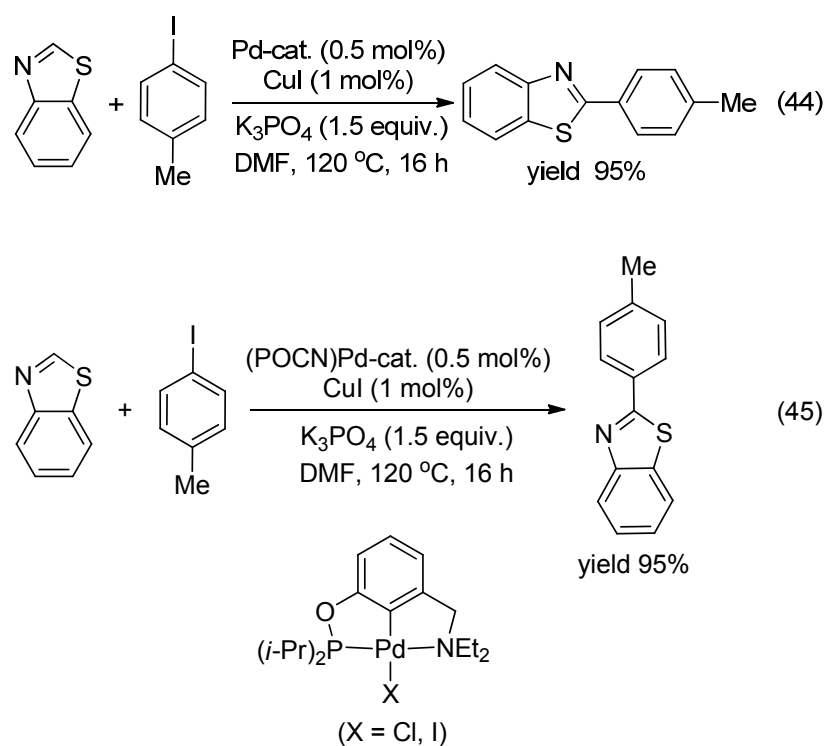

2015 年, 武杰和侯红卫等 ${ }^{[64]}$ 报道了一种铜金属有 机框架 $(\mathrm{Cu}-\mathrm{MOF})$ 结构的催化剂催化的杂芳环 $\mathrm{C}-\mathrm{H}$ 键 活化(Eq. 46). 作者以这种 Cu-MOFs 结构作催化剂, 200 $\mathrm{mol} \% \mathrm{~K}_{2} \mathrm{CO}_{3}$ 作碱, DMF 作溶剂实现了芳杂环和卤代芳 环的直接偶联. 该 MOFs 结构类似多孔沸石, 通过可逆 变换捕捉 $\mathrm{O}_{2}$ 实现这一氧化/还原变化, 从而实现 Ullmann 偶联反应. 相比过渡金属盐催化有着独特的反 应优势，但此反应添加剂用量大、反应温度高

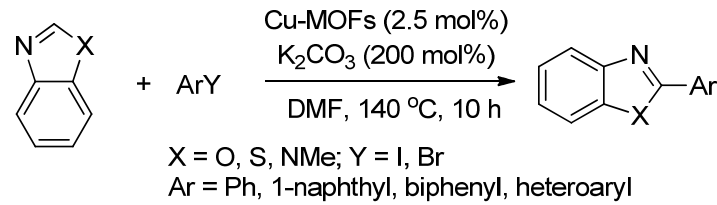

2011 年, 游劲松等 ${ }^{[65]}$ 报道了 $\mathrm{Pd}$ 催化氧化的芳杂环 与吲哚(或吡咯类)的交叉偶联(Eqs. 47, 48). 该体系采用 $\mathrm{Pd}(\mathrm{dppf}) \mathrm{Cl}_{2}, \mathrm{X}-\mathrm{Phos}, \mathrm{CuCl}, \mathrm{Cu}(\mathrm{OAc})_{2} \cdot \mathrm{H}_{2} \mathrm{O}$ 、吡啶结合共 催化, 于 1,4 -二氧六环/DMSO 中催化芳杂环的偶联. 该 反应对各种杂芳结构、吡咯类、吲哚具有广泛的适用性, 且直接实现了 $\mathrm{C}-\mathrm{H}$ 键的活化. 但催化体系太过复杂, 后处理不容易，且采用各种贵金属盐、过渡金属盐，成 本昂贵, 污染大. 

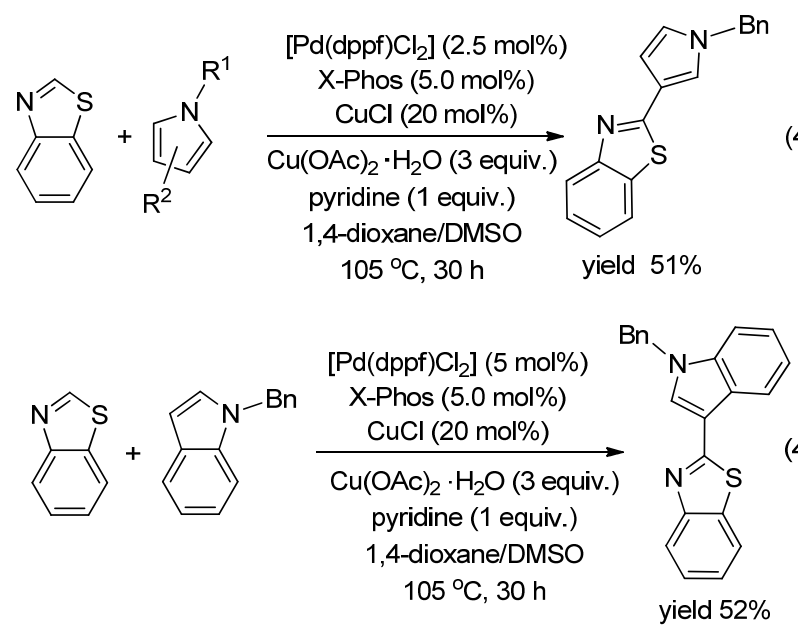

2014 年, 王中夏等 ${ }^{[66]}$ 报道 $\mathrm{Pd}$ 催化的芳基化, 反应 采用 $[\mathrm{Pd}(\pi \text {-allyl }) \mathrm{Cl}]_{2}$ 作催化剂, $\mathrm{PCy}$ 或 $\mathrm{IPr} \bullet \mathrm{HCl}$ 作配体, 有机碱作用下促使芳基季铵盐和芳杂环的偶联(Eq. 49). 该反应通过钯催化 $\mathrm{C}-\mathrm{H} / \mathrm{C}-\mathrm{N}$ 键的断裂, 对各种芳香 季铵盐、䒺环季铵盐具有广泛的适用性, 且得到良好的 产率.
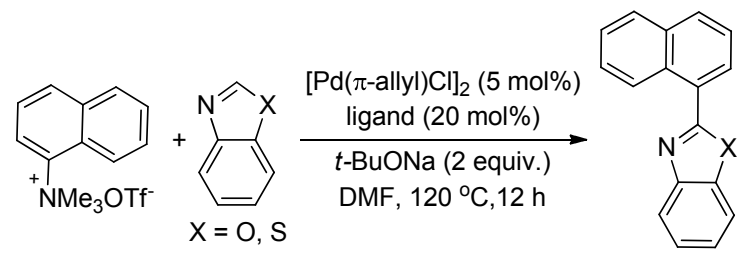

yield $42 \% \sim 97 \%$

2015 年，崔秀玲和吴养洁等 ${ }^{[67]}$ 报道了一种有效的 交叉脱氢偶联反应, 在无金属的状态下, 以空气为氧化 剂, 实现了 $N$-氧喹诺啉和苯并噻(啞)唑的偶联(Eq. 50). 反应体系中仅以叔丁醇锂就实现了该偶联反应, 作者通 过控制实验发现, 喹诺啉中的 $\mathrm{N}-\mathrm{O}$ 键对反应起到至关 重要的作用. 该路线简便、高效、环境友好, 但反应时 间长、反应温度高.

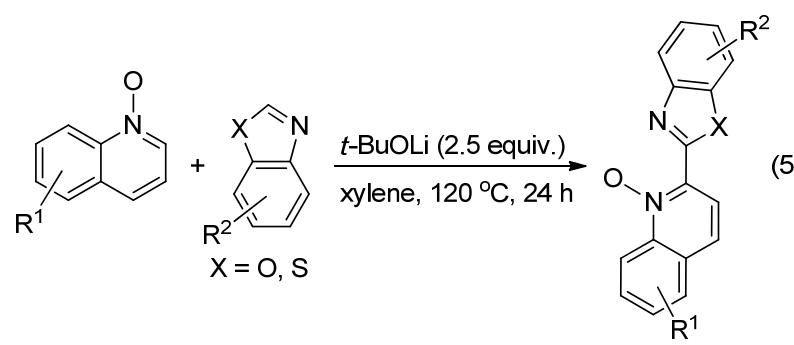

yield $14 \% \sim 95 \%$

2011 年, 刘小刚等 ${ }^{[68]}$ 以 $[\mathrm{Pd}] /[\mathrm{Cu}]$ 催化了芳杂环的芳 基化反应(Eq. 51). 反应在以 $\mathrm{Pd}(\mathrm{OAc})_{2} / \mathrm{Cu}(\mathrm{OAc})_{2}$ 作共催 化剂, 1,10-菲咯啉作配体, $\mathrm{K}_{3} \mathrm{PO}_{4}$ 作碱的条件下, $100{ }^{\circ} \mathrm{C}$
实现了苯并噻唑(苯并噁唑)和芳基硼酸的直接偶联反 应. 该反应体系提供了一条新的合成杂芳和芳烃的偶联 反应路线，且对各种官能团具有很好的容忍性.同年， 王锐等 ${ }^{[69]}$ 报道了 $\mathrm{Cu}$ 催化氧化的 $\mathrm{C}-\mathrm{C}$ 键偶联反应( $\mathrm{Eq}$. $52)$. 该反应以 $10 \mathrm{~mol} \% \mathrm{CuCl}$ 作催化剂, $t$-BuOLi 作碱, 在氧气作用下实现了芳杂环和芳基硼酸酯的交叉偶联 反应. 相比而言，此合成路线反应条件温和、反应时间 短、催化剂廉价且具有很高的分离产率.
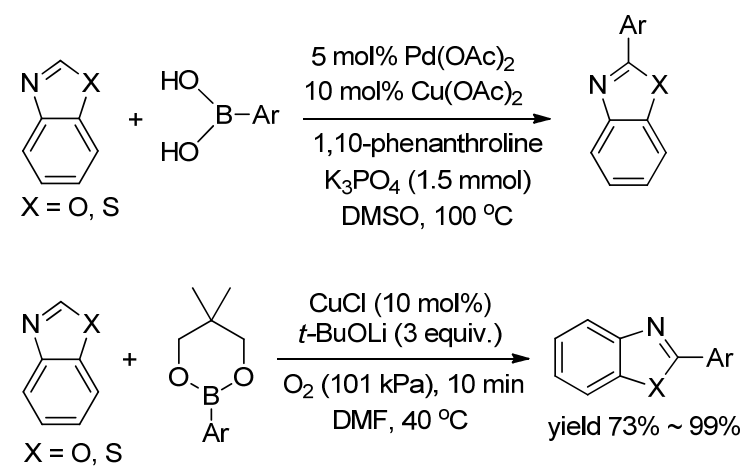

2015 年, Muthusubramanian 等 ${ }^{[70]}$ 也报道了一种有效 的 $\mathrm{Cu}$ 介导 $\mathrm{Pd}$ 催化的脱硫 $\mathrm{C}-\mathrm{C}$ 键交叉偶联(Eq. 53). 反 应中 $\mathrm{Pd}(\mathrm{OAc})_{2}$ 作催化剂, $\mathrm{Cu}(\mathrm{I})$ 噻吩-2-羧酸盐 $(\mathrm{CuTC})$ 作 脱硫试剂, $\mathrm{PPh}_{3}$ 作配体, 实现了噻唑烷-2-硫酮和芳基硼 酸的偶联反应. 反应体系简便、产率高，且芳基硼酸适 用性广，对合成各种取代苯并噻唑提供了一条新思路.

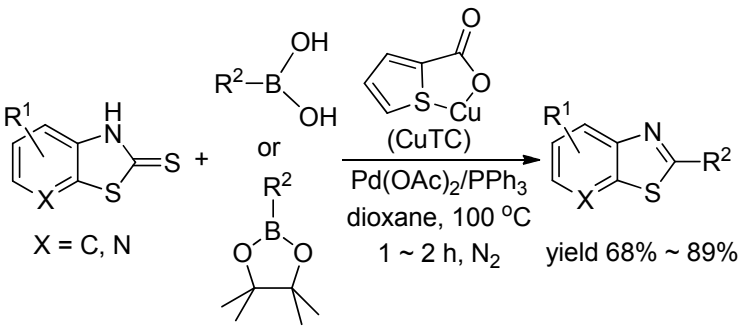

2012 年, 谭泽等 ${ }^{[71]}$ 以 $\mathrm{K}_{2} \mathrm{~S}_{2} \mathrm{O}_{8}$ 介导催化氧化合成了 2芳基化苯并噻唑(Eq. 54). 仅以 $\mathrm{K}_{2} \mathrm{~S}_{2} \mathrm{O}_{8}$ 作氧化剂, $100{ }^{\circ} \mathrm{C}$ 反应 $3 \mathrm{~h}$ 成功合成了 26 个 2-芳基化偶联产物，产率 $24 \% \sim 74 \%$. 该反应避免了贵金属/过渡金属的催化体系， 无需任何配体，氧化剂廉价易得，且首次采用芳醛(苯基 乙醛酸)作为芳基化试剂. 但反应温度高、产率一般.

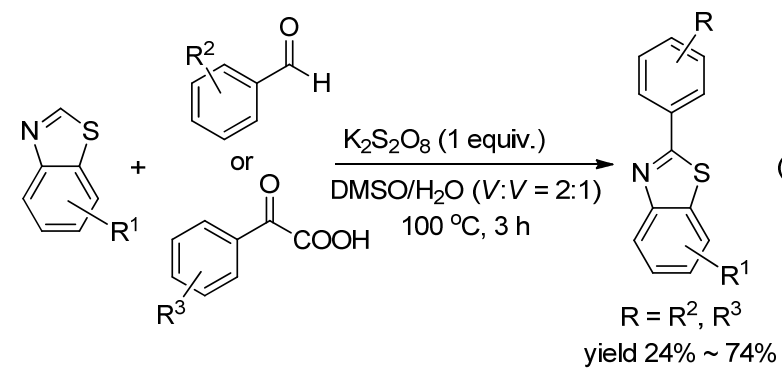


2013 年, 宋秋玲等 ${ }^{[72]}$ 报道了以廉价铜盐作催化剂, 促使苯乙酸脱羧偶联(Eq. 55). 该反应在铜盐的作用下 脱羧然后被氧化成醛, 苯并噻唑在高温下开环, 再和醛 环合生成目标产物. 该体系对各种苯乙酸衍生物具有广 泛的适用性，且具有很好的分离产率. 但路线反应时间 长、反应温度高.

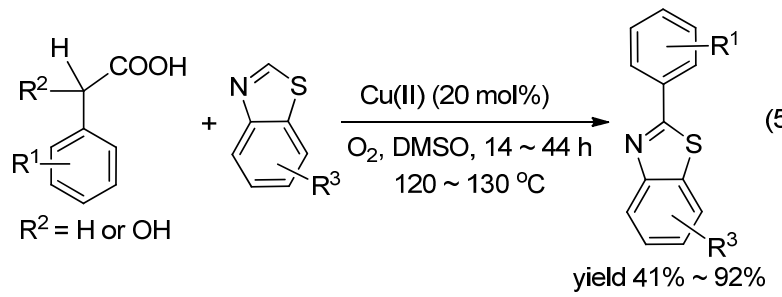

2014 年, Bhanage 等 ${ }^{[73]}$ 以 $\mathrm{Fe}$ 催化有效合成了 2-芳基 苯并噻唑(Eq. 56). 反应体系以 $\mathrm{Fe}\left(\mathrm{NO}_{3}\right)_{3} \cdot 9 \mathrm{H}_{2} \mathrm{O}$ 作催化 剂, $\mathrm{P}(t-\mathrm{Bu})_{3} \cdot \mathrm{HBF}_{4}$ 作配体, 在氧气条件下通过先氧化苯 乙烯成苯甲醛, 苯并噻唑开环再和苯甲醛环合生成目标 产物. 该反应催化剂廉价易得, 氧化剂绿色丰富, 且得 到良好的产率，但存在配体用量大、反应时间长、反应 温度高等不足.

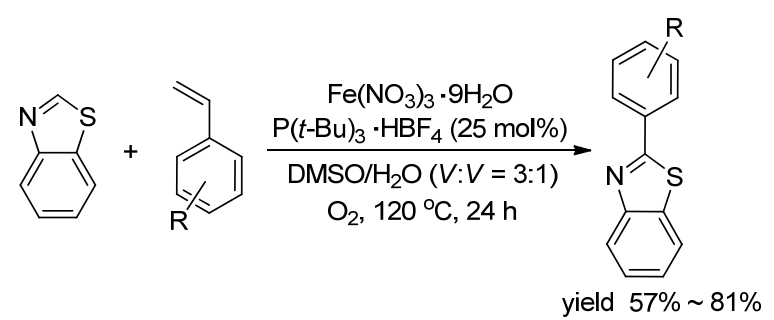

同年, 陈善勇等 ${ }^{[74]}$ 以 $\mathrm{Fe}$ 催化了苯并噻唑芳基化和 芳酰化反应(Eq. 57). 反应以 $\mathrm{FeCl}_{3} \cdot 6 \mathrm{H}_{2} \mathrm{O}$ 作催化剂, $\mathrm{K}_{2} \mathrm{~S}_{2} \mathrm{O}_{8}$ 作氧化剂, 在 $100{ }^{\circ} \mathrm{C}$ 条件下实现了苯并噻唑和 苯甲醇的芳基化反应. 反应也是通过先氧化醇、苯并噻 唑氧化开环、再进行二者环化得目标产物. 相比于同类 型反应，该反应原料廉价易得、反应时间短、无需任何 配体. 随后张慧君等 ${ }^{[75]}$ 以过渡金属 $\mathrm{Cu}$ 催化了芳基化反 应(Eq. 58). 反应以廉价的 $\mathrm{CuCl}_{2}$ 作催化剂, $70 \% \mathrm{TBHP}$ 作氧化剂, 无溶剂条件下实现苯并噻唑和苄醇(芳醛)的 偶联. 此反应机理包括苯并噻唑开环、醛胺偶联、再分 子内环合. 该反应优点在于无溶剂、反应体系温和、方 法简便.

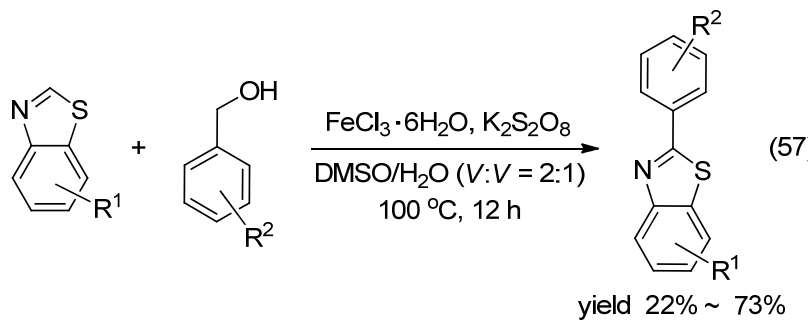

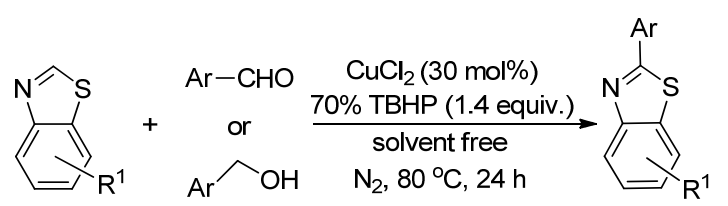

yield $24 \% \sim 83 \%$

2014 年，崔秀玲等 ${ }^{[76]}$ 也报道了 KI 催化的芳基化反 应(Eq. 59). 反应在无金属条件下, 以 $\mathrm{KI}$ 作催化剂, $\mathrm{TBHP}$ 作氧化剂，水作溶剂, $100{ }^{\circ} \mathrm{C}$ 下应 $8 \mathrm{~h}$ 合成了 28 个芳基化产物，产率 36\% 79\%. 该反应体系的优点在 于不使用任何配体、无金属污染、溶剂绿色、反应时间 短. 相比同类型反应，该反应产率不高.

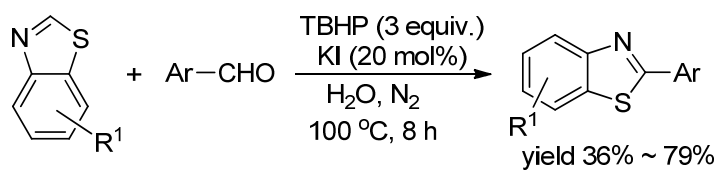

2015 年, 王锐等 ${ }^{[77]}$ 报道了 $\mathrm{Cu}(\mathrm{OTf})_{2} / \mathrm{K}_{2} \mathrm{~S}_{2} \mathrm{O}_{8}$ 共催化 体系, 实现了 2-芳基苯并噻唑的氧化偶联(Eq. 60). 反应 体系通过 $\mathrm{K}_{2} \mathrm{~S}_{2} \mathrm{O}_{8}$ 氧化 $\alpha$-氨基苯乙酸, 再脱羧, 苯并噻唑 在 $\mathrm{K}_{2} \mathrm{~S}_{2} \mathrm{O}_{8}$ /高温条件下开环, 和苯甲醛再环合得目标产 物. 该反应首次探究了 $\alpha$-氨基苯乙酸的氧化偶联，对后 续研究这类反应具有重要意义.

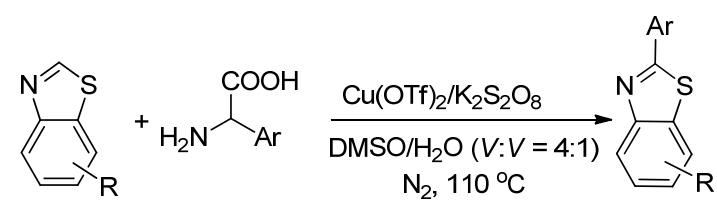

2016 年, Weaver 课题组 ${ }^{[78]}$ 报道了光氧化还原介导 的 $\mathrm{C}-\mathrm{H}$ 键功能化偶联反应(Eq. 61). 该反应以 $0.3 \mathrm{~mol} \%$ fac- $\operatorname{Ir}(\text { ppy })_{3}$ 作光催化剂, $\mathrm{K}_{2} \mathrm{CO}_{3}$ 作碱, Blue LED 灯照射 下实现了 2-溴苯并噻唑和富电子芳烃的交叉偶联反应. 此反应条件温和、操作简单、官能团容忍性好, 且具有 很好的分离产率.

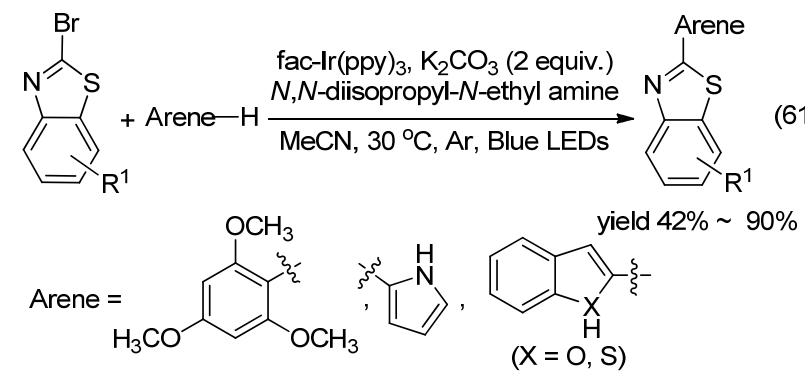

苯并噻唑的直接芳基化反应主要以过渡金属催化 为主，添加配体、氧化剂促进反应的实现，从整个反应 体系看，主要以卤代芳烃、芳醛作芳基化试剂，过渡金 属盐/氧化剂形成的催化体系实现苯并噻唑的芳基化反 
应是一个主要的途径. 虽然这一反应类型能得到很好的 催化效果, 但也存在着金属催化剂带来的污染大、反应 温度高、反应时间长等不足.

\section{4 胺基化的苯并噻唑( $\mathrm{C}-\mathrm{N}$ 键的形成)}

$\mathrm{C}-\mathrm{N}$ 键的形成主要通过交叉偶联反应实现, 其在 合成具有药物活性的产物具有潜在的研究价值. 含芳杂 环的 $\mathrm{C}-\mathrm{N}$ 键偶联产物广泛应用于天然产物合成、农用 化学品、医药以及材料科学领域 ${ }^{[79]}$. 苯并噻唑的胺基化 反应种类很多, 本文简单介绍了近几年合成胺基化的方 法.

2013 年, $\mathrm{Hu}$ 等 ${ }^{[80]}$ 报道了一种含苯并噻唑的具有抑 制磷酸二酯酶 10A (PDE10A)的新化合物(Eq. 62). 反应 在 $\mathrm{Pd}_{2}(\mathrm{dba})_{3}$ 催化下, 叔丁醇钾作碱促使 2-溴苯并噻唑和 4-取代苯胺的 C- $\mathrm{N}$ 键偶联. 该新化合物对 PDE10A 酶 具有良好的抑制作用 $\left(\mathrm{IC}_{50}=4.3 \pm 0.42 \mathrm{nmol} \cdot \mathrm{L}^{-1}\right)$, 且对 人和鼠具有 P-糖蛋白流失率低的优点, 此新药也说明了 苯并噻唑在药物中具有重要的潜在价值.
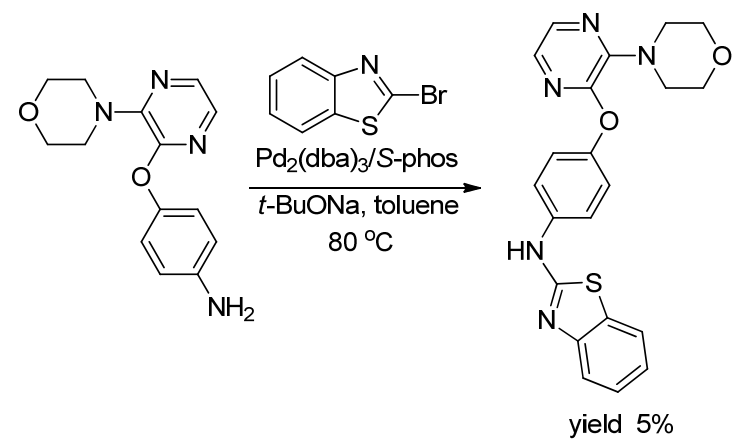

(62)

2014 年, Nageswar 课题组 ${ }^{[81]}$ 以 $\mathrm{Ru} / \mathrm{C}$ 作非均相催化 剂, $t$-BuOLi 作碱, $80{ }^{\circ} \mathrm{C}$ 反应 $8 \mathrm{~h}$ 获得了 54 种目标产物, 产率 58\% 90\% (Eq. 63). 该反应的优点在于操作简单、 不使用任何配体、对水和空气不敏感、底物适用性广且 催化剂可重复利用多次仍有活性. 同年, 该课题组 ${ }^{[82]}$ 报道磁性纳米材料 $\mathrm{CuFe}_{2} \mathrm{O}_{4}$ 催化的 $\mathrm{C}-\mathrm{N}$ 键偶联反应 (Eq. 64). 反应体系以 $\mathrm{CuFe}_{2} \mathrm{O}_{4}$ 作催化剂, $\mathrm{Cs}_{2} \mathrm{CO}_{3}$ 作碱, $110{ }^{\circ} \mathrm{C}$ 反应 $15 \mathrm{~h}$ 实现苯并噻唑和胺的直接偶联. 相比 $\mathrm{Ru} / \mathrm{C}$ 催化体系, 该纳米催化剂催化效果一般、反应条件 也不温和. 但该方法说明, 磁性纳米材料能够催化促进

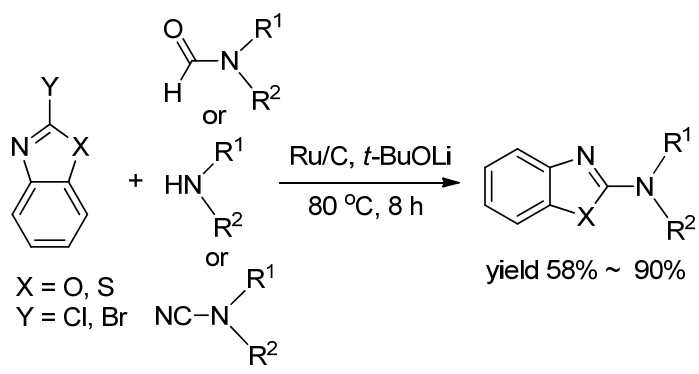

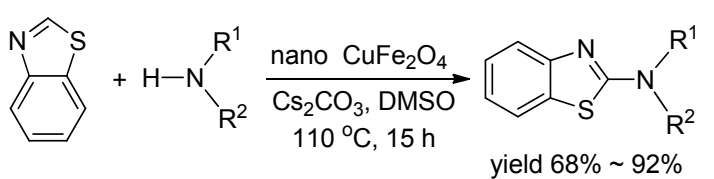

$\mathrm{C}-\mathrm{N}$ 键的偶联, 且该磁性材料可回收重复利用, 对探 究纳米材料催化这类反应具有重要意义.

2016 年, Nageswar 课题组 ${ }^{[83]}$ 再次报道了类似的 2卤代苯并噻唑和胺的偶联反应(Eq. 65). 该反应体系既 不用金属催化剂，也不用任何配体，更不使用任何碱， 仅在水作溶剂、室温下进行偶联反应. 这种理想化的合 成方法类似于酸碱中和, 为合成 2-胺基化苯并噻唑提供 了一条绿色途径.

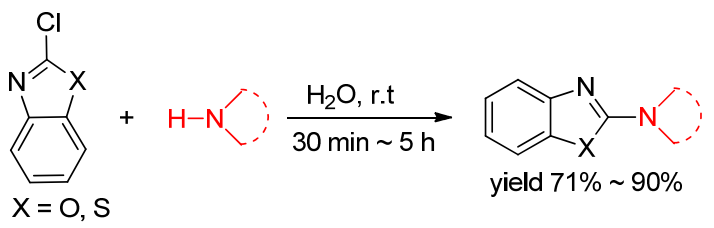

\section{5 磷酸化的苯并噻唑(C-P 键的形成)}

在过去几十年, 有机磷化合物在生物化学、材料化 学、有机合成和催化领域得到广泛的应用 ${ }^{[84]}$. 通常, 含 磷取代基在生物、药物和功能材料方面具有重要作用, 也作为磷配体或直接作官能团应用在过渡金属催化 中 $^{[85]}$. 基于此, 2-位磷酸化的苯并噻唑化合物在药物研 发和有机合成领域也受到广泛关注. 因此, 本文简单介 绍近年来 2-位磷酸化苯并噻唑化合物的合成及应用.

2012 年, 李福伟等 ${ }^{[86}$ 报道了首个 Pd-催化直接磷酸 化作用(Eq. 66). 反应以 $\mathrm{Pd}(\mathrm{OAc})_{2}$ 作催化剂, 脯氨酸 $(\mathrm{L1})$ 或 2,2-二吡啶(L2)作配体, $\mathrm{K}_{2} \mathrm{~S}_{2} \mathrm{O}_{8}$ 作氧化剂, $100{ }^{\circ} \mathrm{C}$ 反应 $24 \mathrm{~h}$ 实现了芳杂环和磷酸酯的直接偶联. 该方法通过氧 化裂解 $\mathrm{C}-\mathrm{H}$ 键断裂, 实现了芳杂环的 $\mathrm{C}-\mathrm{H}$ 键活化. 但 反应体系复杂、催化剂昂贵、反应温度高、反应时间长. 同年，杨尚东等 ${ }^{[87}$ 报道了 $\mathrm{Ni}$ 催化 $\mathrm{C}-\mathrm{P}$ 键的交叉偶联 (Eq. 67). 反应以 $\mathrm{NiCl}_{2}\left(\mathrm{PPh}_{3}\right)_{2}$ 作催化剂, $\mathrm{K}_{2} \mathrm{CO}_{3}$ 作碱, DMF 作溶剂, $50{ }^{\circ} \mathrm{C}$ 下反应实现了卤代芳杂环和芳基磷 酸的交叉偶联反应. 该反应操作简单、反应条件温和, 对各种卤代芳、卤代杂芳具有广泛的适用性，且具有良 好的分离产率.
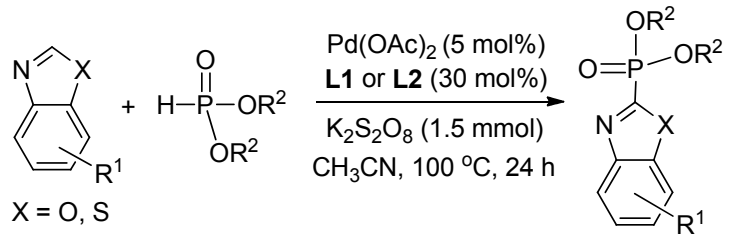

yield $41 \% \sim 83 \%$ 


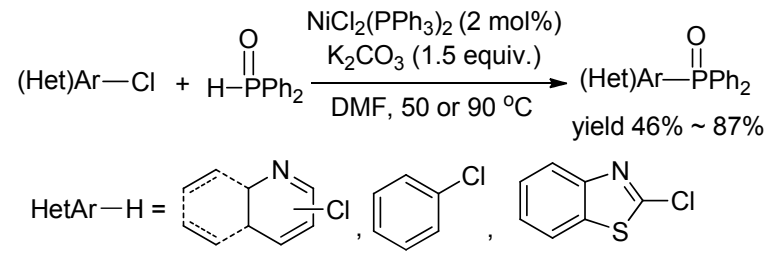

2014 年, Chamarthi 等 ${ }^{[88]}$ 以 $\mathrm{LaCl}_{3} \cdot 7 \mathrm{H}_{2} \mathrm{O}$ 催化的 Michaelis-Arbuzov 反应, 实现了 $\mathrm{C}-\mathrm{P}$ 键的偶联(Eq. 68). 作者以 $\mathrm{LaCl}_{3} \cdot 7 \mathrm{H}_{2} \mathrm{O}$ 作催化剂, 无溶剂状态下, 促进卤代 芳杂环和二甲氧基苯基膦的直接交叉偶联, 该反应避免 毒性催化剂和溶剂的危害, 反应条件温和、且产率高, 并且作者对各种偶联产物进行生物活性测试, 具有很好 的抗菌活性. 同年, 陈晓岗和曲凌波等 ${ }^{[89]}$ 报道了过氧化 物催化的 C-P 键的偶联反应(Eq. 69). 反应以过氧化二 叔丁基(DTBP)作氧化剂, 乙腈作溶剂, $80{ }^{\circ} \mathrm{C}$ 反应 $30 \mathrm{~h}$ 实现了苯并噻唑和磷酸酯的交叉脱氢偶联. 此催化体系 克服了过渡金属、贵金属催化的不足，但反应时间较长.
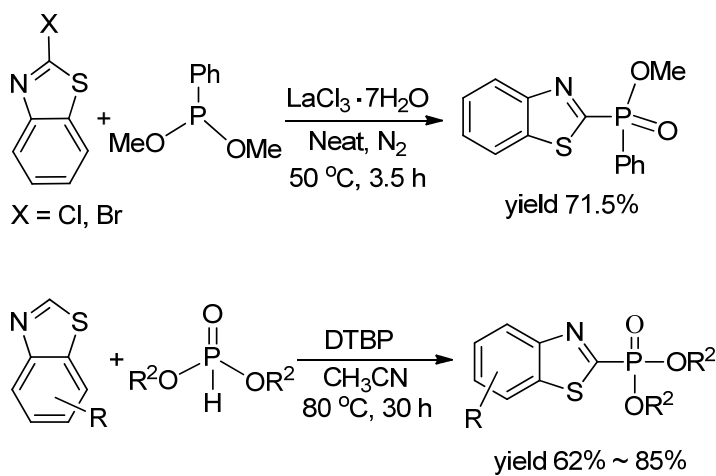

2015 年, 张慧君等 ${ }^{[00]}$ 报道了 $\mathrm{Ag}$ 介导的直接磷酸化 作用, 反应以 $\mathrm{AgNO}_{3}$ 作催化氧化剂, 乙腈作溶剂实现了 苯并噻唑和二芳基氧磷的氧化偶联(Eq. 70). 该体系比 Pd 催化磷酸化反应 ${ }^{[91]}$ 简便, 不需额外添加氧化剂, 但相 比于 DTBP 作氧化剂，硝酸银比较昂贵.

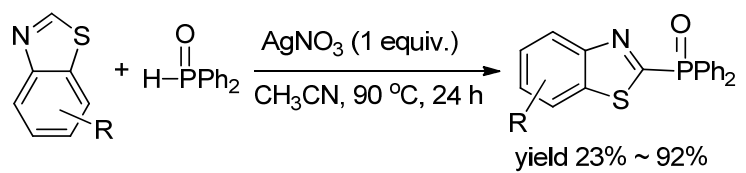

2016 年, 吴否等 ${ }^{[92]}$ 在无金属、无溶剂状态下, 直接 自氧化形成 $\mathrm{C}-\mathrm{P}$ 键. 该反应仅以氧气作为氧化源, $65{ }^{\circ} \mathrm{C}$ 反应 $18 \mathrm{~h}$ 就得到杂芳 $\mathrm{C}-\mathrm{P}$ 键的偶联(Eq. 71). 该 反应通过氧气使二苯基氧膦变成磷酸过氧化物, 产生过 氧自由基和二苯基膦自由基, $\cdot \mathrm{OOH}$ 自由基氧化芳杂环 形成自由基, 再自由基偶联形成目标产物. 该反应体系 简便、绿色环保、产率高. 同年, 该课题组 ${ }^{\left[{ }^{[3]}\right]}$ 再次报道 了一种以染料作光敏剂催化的芳杂环 $\mathrm{C}-\mathrm{H}$ 键功能化偶
联反应(Eq. 72). 该反应体系采用无金属催化，以 5 mol\% Eosin B 作光敏剂, 氯仿作溶剂, 11 W LED 灯照射 下，实现了苯并噻唑和芳基磷酸的交叉脱氢偶联. 此反 应合成路线简便, 无任何氧化剂和添加剂, 仅有的副产 物是 $\mathrm{H}_{2}$, 且反应对各种官能团具有很好的适应性，原子 经济利用率高, 是一条绿色环保的合成路线.
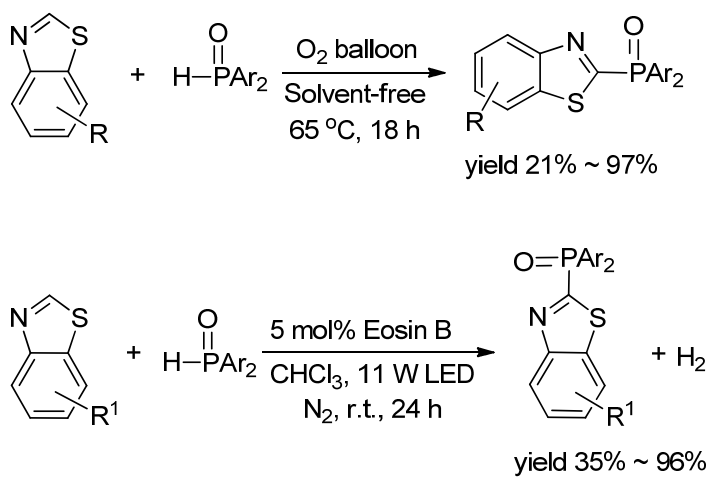

随后 2016 年, 王官武等 ${ }^{[94]}$ 也报道了 $\mathrm{Mn}$-促进的交 叉偶联磷酸化反应(Eq. 73). 反应以 $\mathrm{Mn}(\mathrm{OAc})_{3} \cdot 2 \mathrm{H}_{2} \mathrm{O}$ 作 催化剂, 球磨条件下, 实现了苯并噻唑的磷酸化. 相比 同类反应，该体系克服了有机溶剂的污染，不添加任何 氧化剂, 也无配体, 是一条绿色环保的路径; 能室温反 应，反应时间短，以空气作氧化剂，是一类反应温和的 催化体系; 且对官能团具有很好的适应性.

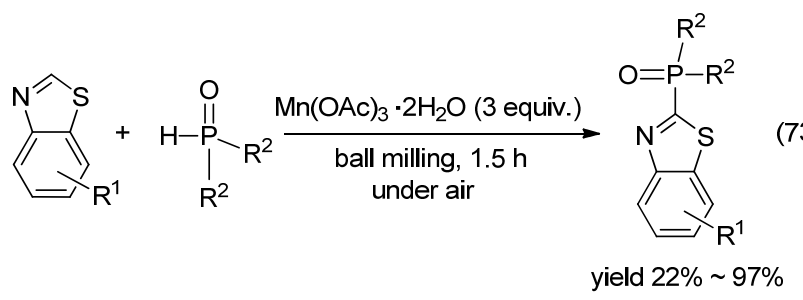

\section{6 结论与展望}

综上所述，2-位官能团化合成 2-取代苯并噻唑的合 成方法很多，主要有过渡金属催化、金属氧化物催化、 强碱催化以及逐渐被研究的可见光介导催化. 合成的目 标产物主要有烷基化、酰基化、芳基化、胺基化和磷酸 化等偶联产物. 相对于缩合环化方法, 2-位官能团化法 合成 2-取代苯并噻唑具有设计连接方便、反应体系简 便、原料易得、原子利用率高等优点.

随着苯并噻唑衍生物的抗菌、杀虫、抗癌等各种生 物活性的发现, 2-取代苯并噻唑在医药和农药等领域的 应用日益广泛, 对其合成方法的研究也越来越多. 纵观 全文, 2-位官能团化合成 2-取代苯并噻唑主要有两种反 应机理: 一种是直接交叉脱氢偶联, 另一种是噻唑先开 环再环合．总的来说，大多采用过渡金属盐、贵金属盐 
在高温条件下实现反应, 而且反应时间较长, 相比而言 污染大、催化剂贵、能耗也高. 从文中少量的可见光介 导催化的反应中可以看出, 以自由基反应的可见光催化 室温条件下就能进行, 克服了反应中的高温能耗; 环境 友好的光敏剂种类也繁多, 可以替代过渡金属. 但可见 光催化目前仍处在研究的初期, 有待我们不断深入研 究, 因此利用可见光催化的自由基反应合成 2-取代苯并 噻唑的方法研究尤其值得关注.

\section{Referenes}

[1] Wang, H. L.; Ruan, L. L.; Chen, Y.; Liu, X. H.; Weng, J. Q. Chin. J. Org. Chem. 2014, 34, 419 (in Chinese). (王海林, 阮铃莉, 陈勇, 刘幸海, 翁建全, 有机化学, 2014, 34, 419.)

[2] Weng, J. Q.; Huang, H.; Tan, C. X.; Liu, X. H.; Cu, W. S.; Chen, J. Chin. J. Org. Chem. 2012, 32, 957 (in Chinese). (翁建全, 黄华, 谭成侠, 刘幸海, 储为盛, 陈杰, 有机化学, 2012, 32, 957.)

[3] Facchinetti, V.; Reis, R. R.; Gomes, C. R. B.; Vasconcelos, T. R. A. Mini-Rev. Org. Chem. 2012, 9, 44.

[4] Weekes, A.; Westwell, A. Curr. Med. Chem. 2009, 16, 2430.

[5] Mouri, T.; Tokumura, J.; Kochi, S.; Fukui, H.; Nakano, J.; Ando, T. Nippon Noyaku Gakkaishi 2002, 27, 353.

[6] Debnatch, S. C.; Basu, D. K. J. Appl. Polym. Sci. 1994, 52, 597.

[7] Chevrie, D.; Lequeux, T.; Demoute, J. P.; Pazenok, S. Tetrahedron Lett. 2003, 44, 8127.

[8] Hofmann, A. W. Ber. Dtsch. Chem. Ges. 1879, 12, 1126.

[9] Li, Y.; Wang, Y. L. Chin. J. Org. Chem. 2006, 26, 878 (in Chinese). (李炎, 王玉炉, 有机化学, 2006, 26, 878.)

[10] Zu, N.; Zhang, Z. W.; Gao, M.; Han, L. M.; Suo, Q. L.; Hong, H. L. Chin. J. Org. Chem. 3013, 33, 1423 (in Chinese). (竺宁, 张志伟, 高敏, 韩利民, 索全伶, 洪海龙, 有机化学, 2013, 33, 1423.)

[11] Nishio, T.; Mori, Y.; Iida, I.; Hosomi, A. HeIv. Chim. Acta 1994, 77, 981.

[12] Imahori, T.; Kondo, Y. J. Am. Chem. Soc. 2003, 125, 8082.

[13] Inamoto, K.; Okawa, H.; Taneda, H.; Sato, M.; Hirono, Y.; Yonemoto, M.; Kikkawa, S.; Kondo, Y. Chem. Commun. 2012, 48, 9771.

[14] Popov, I.; Do, H. Q.; Daugulis, O. J. Org. Chem. 2009, 74, 8309.

[15] Inamoto, K.; Okawa, H.; Kikkawa, S.; Kondo, Y. Tetrahedron 2014, $70,7917$.

[16] Shen, H. C.; Ding, F. X.; Colletti, S. L. Org. Lett. 2006, 8, 1447.

[17] Mukai, T.; Hirano, K.; Satoh, T.; Miura, M. Org. Lett. 2010, 12, 1360 .

[18] Gottumukkala, A. L.; Derridj, F.; Djebbar, S.; Doucet, H. Tetrahedron Lett. 2008, 49, 2926.

[19] Gustafsson, M.; Jensen, J.; Bertozzi, S. M.; Currier, E. A.; Ma, J. N.; Burstein, E. S.; Olsson, R. Bioorg. Med. Chem. Lett. 2010, 20, 5918.

[20] Zhao, X.; Wu, G. J.; Zhang, Y.; Wang, J. B. J. Am. Chem. Soc. 2011, 133, 3296.

[21] Ojha, D. P.; Prabhu, K. R. J. Org. Chem. 2012, 77, 11027.

[22] Yao, T.; Hirano, K.; Satoh, T.; Miura, M. Angew. Chem., Int. Ed. 2012, 51, 775 .

[23] Zhang, J. L.; Yang, Y. H.; Wang, M.; Lin, L.; Wang, R. Tetrahedron Lett. 2012, 53, 6893.

[24] Singh, A.; Arora, A.; Weaver, J. D. Org. Lett. 2013, 15, 5390

[25] Das, M.; O'Shea, D. F. J. Org. Chem. 2014, 79, 5595.

[26] Mei, H. B.; Dai, Y. L.; Wu, L. M.; Soloshonok, V. A.; Han, J. L.; Pan, Y. Eur. J. Org. Chem. 2014, 12, 2429.

[27] Dai, Y. L.; Xie, C.; Wu, L. M.; Mei, H. B.; Soloshonok, V. A.; Han, J. L.; Pan, Y. RSC Adv. 2015, 5, 3491.
[28] Klapars, A.; Waldman, J. H.; Campos, K. R.; Jensen, M. S.; McLaughlin, M.; Chung, J. Y. L.; Cvetovich, R. J.; Chen, C. Y. J. Org. Chem. 2005, 70, 10186.

[29] Xie, P.; Huang, H. M.; Xie, Y. J.; Guo, S. M.; Xia, C. G. Adv. Synth. Catal. 2012, 354, 1692.

[30] Wang, G. W.; Zhou, A. X.; Wang, J. J.; Hu, R. B.; Yang, S. D. Org. Lett. 2013, 15, 5270.

[31] Zhao, W. M.; Chen, X. L.; Yuan, J. W.; Qu, L. B.; Duan, L. K.; Zhao, Y. F. Chem. Commun. 2014, 50, 2018.

[32] Paul, S.; Guin, J. Chem. Eur. J. 2015, 21, 17618.

[33] Wang, J.; Li, J.; Huang, J. B.; Zhu, Q. J. Org. Chem. 2016, 81, 3017.

[34] Crossley, S. W. M.; Martinez, R. M.; Zuluaga, S. G.; Shenvi, R. A. Org. Lett. 2016, 18, 2620.

[35] Xie, Z. Y.; Cai, Y. P.; Hu, H. W.; Lin, C.; Jiang, J. L.; Chen, Z. X.; Wang, L. Y.; Pan, Y. Org. Lett. 2013, 15, 4600.

[36] Devari, S.; Shah, B. A. Chem. Commun. 2016, 52, 1490

[37] Pinkeron, F. H.; Thames, S. F. J. Heterocycl. Chem. 1971, 8, 257.

[38] Myllymaki, M. J.; Saario, S. M.; Kataja, A. O.; Castillo-Melendez, J. A.; Nevalainen, J. R. O.; Jarvinen, T.; Koskinen, A. M. P. J. Med. Chem. 2007, 50, 4236.

[39] He, T.; Li, H. J.; Li, P. H.; Wang, L. Chem. Commun. 2011, 47, 8946.

[40] Yin, Z. W.; Zhang, Z. X.; Kadow, J. F.; Meanwell, N. A.; Wang, T. J. Org. Chem. 2004, 69, 1364.

[41] Wang, X. B.; Wang, Z. G. Tetrahedron 2011, 67, 3406.

[42] Liu, J. M.; Zhang, X.; Yi, H.; Liu, C.; Liu, R.; Zhang, H.; Zhuo, K. L.; Lei, A. W. Angew. Chem., Int. Ed. 2015, 54, 1261.

[43] Gao, Q. H.; Wu, X.; Jia, F. C.; Liu, M. C.; Zhu, Y. P.; Cai, Q.; Wu, A. X. J. Org. Chem. 2013, 78, 2792.

[44] Liu, S. W.; Chen, R.; Chen, H.; Deng, G. J. Tetrahedron Lett. 2013, $54,3838$.

[45] Feng, Q.; Song, Q. L. Adv. Synth. Catal. 2014, 356, 2445.

[46] Yang, K.; Zhang, C.; Wang, P.; Zhang, Y.; Ge, H. B. Chem. Eur. J. 2014, 20, 7241.

[47] Sharma, S.; Khan, I. A.; Saxena, A. K. Adv. Synth. Catal. 2013, 355,673 .

[48] Yang, K.; Chen, X. Y.; Wang, Y. Q.; Li, W. Q.; Kadi, A. A.; Fun, H. K.; Sun, H.; Zhang, Y.; Li, G. G.; Lu, H. J. J. Org. Chem. 2015, 80, 11065 .

[49] Hu, E.; Kunz, R. K.; Chen, N.; Rumfelt, S. N.; Siegmund, A.; Andrews, K.; Chmait, S.; Zhao, S. R.; Davis, C.; Chen, H.; Zeiner, D. L.; Ma, J.; Biorn, C.; Shi, J. X.; Porter, A.; Treanor, J.; Allen, J. R. J. Med. Chem. 2013, 56, 8781 .

[50] Chen, X. L.; Li, X.; Qu, L. B.; Tang, Y. C.; Mai, W. P.; Wei, D. H.; Bi, W. Z.; Duan, L. K.; Sun, K.; Chen, J. Y.; Ke, D. D.; Zhao, Y. F. J. Org. Chem. 2014, 79, 8407.

[51] Sharma, U. K.; Sharma, N.; Xu, J.; Song, G. H.; Eycken, E. V. V. Chem. Eur. J. 2015, 21, 4908.

[52] Nagasawa, Y.; Tachikawa, Y.; Yamaguchi, E.; Tada, N.; Miura, T.; Itoh, A. Adv. Synth. Catal. 2016, 358, 178.

[53] Zhang, Y. Q.; Teuscher, K. B.; Ji, H. T. Chem. Sci. 2016, 7, 2111.

[54] Hassan, J.; Sévignon, M.; Gozzi, C.; Schulz, E.; Lemaire, M. Chem. Rev. 2002, 102, 1359.

[55] Hachiya, H.; Hirano, K.; Satoh, T.; Miura, M. Org. Lett. 2009, 11, 1737.

[56] Canivet, J.; Yamaguchi, J.; Ban, I.; Itami, K. Org. Lett. 2009, 11, 1733.

[57] Begouin, J. M.; Rivard, M.; Gosmini, C. Chem. Commun. 2010, 46, 5972.

[58] Saha, D.; Adak, L.; Ranu, B. C. Tetrahedron Lett. 2010, 51, 5624.

[59] Yan, X. M.; Mao, X. R.; Huang, Z. Z. Heterocycles 2011, 83, 1371.

[60] Yamamoto, T.; Muto, K.; Komiyama, M.; Canivet, J.; Yamaguchi, J.; Itami, K. Chem. Eur. J. 2011, 17, 10113.

[61] Shin, S.; Kim, Y.; Kim, K.; Hong, S. Org. Biomol. Chem. 2014, 12, 5719.

[62] Pandey, D. K.; Khake, S. M.; Gonnade, R. G.; Punji, B. RSC Adv. 2015, 5, 81502. 
[63] Khake, S. M.; Jagtap, R. A.; Dangat, Y. B.; Gonnade, R. G.; Vanka, K.; Punji, B. Organometallics 2016, 35, 875.

[64] Huang, C.; Wu, J.; Song, C. J.; Ding, R.; Qiao, Y.; Hou, H. W.; Chang, J. B.; Fan, Y. T. Chem. Commun. 2015, 51, 10353.

[65] Wang, Z.; Li, K. Z.; Zhao, D. B.; Lan, J. B.; You, J. S. Angew. Chem., Int. Ed. 2011, 50, 5365.

[66] Zhu, F.; Tao, J. L.; Wang, Z. X. Org. Lett. 2015, 17, 4926.

[67] Chen, X. P.; Cui, X. L.; Yang, F. F.; Wu, Y. J. Org. Lett. 2015, 17, 1445.

[68] Ranjit, S.; Liu, X. G. Chem. Eur. J. 2011, 17, 1105.

[69] Yang, F. Z.; Xu, Z. Q.; Wang, Z.; Yu, Z. K.; Wang, R. Chem. Eur. J. 2011, 17, 6321.

[70] Rajaguru, K.; Mariappan, A.; Manjusri, R.; Muthusubramanian, S.; Bhuvanesh, N. RSC Adv. 2015, 5, 86832.

[71] Yang, Z. Y.; Chen, X.; Wang, S. Z.; Liu, J. D.; Xie, K.; Wang, A. W.; Tan, Z. J. Org. Chem. 2012, 77, 7086.

[72] Song, Q. L.; Feng, Q.; Zhou, M. X. Org. Lett. 2013, 15, 5990.

[73] Khemnar, A. B.; Bhanage, B. M. RSC Adv. 2014, 4, 8939.

[74] Wang, J.; Zhang, X. Z.; Chen, S. Y.; Yu, X. Q. Tetrahedron 2014, $70,245$.

[75] Zhang, M. L.; Lu, W. T.; Ruan, W. Q.; Zhang, H. J.; Wen, T. B. Tetrahedron Lett. 2014, 55, 1806.

[76] Gao, Y. Y.; Song, Q. L.; Cheng, G. L.; Cui, X. L. Org. Biomol. Chem. 2014, 12, 1044

[77] Wang, R.; An, C. H.; Li, Y.; Zhao, Y.; Wang, T.; Li, A. Tetrahedron Lett. 2015, 56, 2077.

[78] Arora, A.; Weaver, J. D. Org. Lett. 2016, 18, 3996.

[79] Hili, R.; Yudin, A. K. Nat. Chem. Biol. 2006, 2, 284.

[80] Hu, E.; Kunz, R. K.; Chen, N.; Rumfelt, S. N.; Siegmund, A.; Andrews, K.; Chmait, S.; Zhao, S. R.; Davis, C.; Chen, H.; Zeiner, D.
L.; Ma, J.; Biorn, C.; Shi, J. X.; Porter, A.; Treanor, J.; Allen, J. R.; J. Med. Chem. 2013, 56, 8781 .

[81] Reddy, K. H. V.; Anil, Kumar. B. S. P.; Reddy, V. P.; Kumar, R. U.; Nageswar, Y. V. D. RSC Adv. 2014, 4, 45579.

[82] Satish, G.; Reddy, K. H. V.; Anil, B. S. P.; Shankar, J.; Kumar, R. U.; Nageswar, Y. V. D. Tetrahedron Lett. 2014, 55, 5533.

[83] Kumar, R. U.; Reddy, K. H. V.; Anil-Kumar, B. S. P.; Satish, G.; Reddy, V. P.; Nageswar, Y. V. D. Tetrahedron Lett. 2016, 57, 637.

[84] Demmer, C. S.; Krogsgaard-Larsen, N.; Bunch, L. Chem. Rev. 2011, 111, 7981.

[85] Zhang, H.; Hu, R. B.; Zhang, X. Y.; Li, S. X.; Yang, S. D. Chem. Commun. 2014, 50, 4686.

[86] Hou, C. D.; Ren, Y. L.; Lang, R.; Hu, X. X.; Xia, C. G.; Li, F. W. Chem. Commun. 2012, 48, 5181.

[87] Zhang, H. Y.; Sun, M.; Ma, Y. N.; Tian, Q. P.; Yang, S. D. Org. Biomol. Chem. 2012, 10, 9627.

[88] Golla, M.; Syed, R.; Katla, V. R.; Devineni, S. R.; Kondapalli, N.; Chamarthi, N. R. J. Chem. Sci. 2014, 126, 117.

[89] Chen, X. L.; Li, X.; Qu, L. B.; Tang, Y. C.; Mai, W. P.; Wei, D. H.; Bi, W. Z.; Duan, L. K.; Sun, K.; Chen, J. Y.; Ke, D. D.; Zhao, Y. F. J. Org. Chem. 2014, 79, 8407.

[90] Zhang, H. J.; Lin, W. D.; Wu, Z. J.; Ruan, W. Q.; Wen, T. B. Chem. Commun. 2015, 51, 3450.

[91] Feng, C. G.; Ye, M. C.; Xiao, K. J.; Li, S. H.; Yu, J. Q. J. Am. Chem. Soc. 2013, 135, 9322.

[92] Luo, K.; Chen, Y. Z.; Chen, L. X.; Wu, L. J. Org. Chem. 2016, 81, 4682.

[93] Luo, K.; Chen, Y. Z.; Yang, W. C.; Zhu, J.; Wu, L. Org. Lett. 2016, $18,452$.

[94] Li, L.; Wang, J. J.; Wang, G. W. J. Org. Chem. 2016, 81, 5433.

(Zhao, C.) 